\title{
Synthesis, X-ray and Spectroscopic Study of Dissymmetric Tetrahedral Zinc(II) Complexes from Chiral Schiff Base Naphthaldiminate Ligands with Apparent Exception to the ECD Exciton Chirality
}

\author{
Mohammed Enamullah, ${ }^{\text {a,d* }}$ Gamall Makhloufi ${ }^{\mathrm{b}}$, Rifat Ahmed ${ }^{\text {a }}$, Baitul Alif Joy ${ }^{\mathrm{a}}$, Mohammad \\ Ariful Islam ${ }^{\text {a }}$, Daniele Padula ${ }^{\mathrm{c}}$, Howard Hunter, ${ }^{\mathrm{d}}$ Gennaro Pescitelli ${ }^{\mathrm{c}, *}$ and Christoph Janiak \\ b,* \\ ${ }^{a}$ Department of Chemistry, Jahangirnagar University, Dhaka-1342, Bangladesh \\ ${ }^{\mathrm{b}}$ Institut für Anorganische Chemie und Strukturchemie, Universität Düsseldorf, Universitätsstr. \\ 1, D-40225 Düsseldorf, Germany. \\ ${ }^{\mathrm{c}}$ Department of Chemistry, University of Pisa, via Moruzzi 13, 56124 Pisa Italy. \\ ${ }^{\mathrm{d}}$ Department of Chemistry, York University, 4700 Keele Street, Toronto, Canada.
}

\begin{abstract}
Bidentate enantiopure Schiff base ligands, $(R$ or $S)$-N-1-(Ar)ethyl-2-oxo-1naphthaldiminate ( $R$ or $S$-N^ $\mathrm{N}^{\wedge}$ ) diastereoselectively provide $\Lambda$ - or $\Delta$-chiral-at-metal fourcoordinated $\mathrm{Zn}\left(R \text { or } S-\mathrm{N}^{\wedge} \mathrm{O}\right)_{2} \quad \mathrm{Ar}=\mathrm{C}_{6} \mathrm{H}_{5} ; \mathrm{Zn}-1 R$ or $\mathrm{Zn}-1 S$, and $p-\mathrm{C}_{6} \mathrm{H}_{4} \mathrm{OMe} ; \mathrm{Zn}-2 R$ or $\left.\mathrm{Zn}-2 S\right\}$. Two $R$ or $S$-N^O-chelate ligands coordinate to the $\operatorname{zinc}(\mathrm{II})$ in a tetrahedral mode and induce $\Lambda$ or $\Delta$-configuration at the zinc metal center. In the solid-state, the $R$ - or S-ligand diastereoselectively gives $\Lambda$ - or $\Delta-\mathrm{Zn}$ configuration, respectively and forms enantiopure crystals. Single crystal structure determinations show two symmetry-independent molecules (A and $B$ ) in each asymmetric unit to give $Z^{\prime}=2$ structures. Electronic circular dichroism (ECD) spectra show the expected mirror image relationship resulting from diastereomeric excess towards the $\Lambda$-Zn for $R$-ligands and $\Delta-\mathrm{Zn}$ for $S$-ligands in solution. ECD spectra are well reproduced by TDDFT calculations, while the application of the exciton chirality method, in the common point-dipole approximation, predicts the wrong sign for the long-wavelength couplet. A dynamic diastereomeric equilibrium $(\Lambda v s . \Delta)$ prevails for both $R$ - and $S$-ligand-metal complexes in solution, respectively, evidenced by ${ }^{1} \mathrm{H}$ NMR spectroscopy. Variable temperature ${ }^{1} \mathrm{H}$ NMR spectra show a temperature-dependent shift of the diastereomeric equilibrium, and confirm $\Delta-\mathrm{Zn}$ configuration (for $S$-ligand) to be the most stable one and favored at low temperatures. DSC analyses provide quantitative diastereomeric excess at solid state for $\mathrm{Zn}-2 R$ and $\mathrm{Zn}-2 S$, which is comparable to the solution studies.
\end{abstract}




\section{INTRODUCTION}

Transition metal complexes with chiral $N^{\wedge} O$-chelate Schiff base ligands are of continued interest $^{1-12}$ and have been used efficiently as chiral catalysts. ${ }^{13-14} \mathrm{We}$ have recently paid attention to the syntheses, characterization, diastereoselectivity and molecular structures of four-coordinated non-planar chiral $\mathrm{M}\left(R-\text { or } S-\mathrm{N}^{\wedge} \mathrm{O}\right)_{2}$ complexes $\left(\mathrm{N}^{\wedge} \mathrm{O}=\right.$ chiral deprotonated Schiff base ligands, $\mathrm{M}=\mathrm{Rh} / \mathrm{Cu} / \mathrm{Ni} / \mathrm{Zn}) .{ }^{15-28}$ In the formation of tetrahedral or distorted tetrahedral/square-planar complexes containing two chiral $\mathrm{N}^{\wedge} \mathrm{O}$-chelate units, diastereoselectivity plays a major role because the resulting $C_{2}$-symmetrical molecules may show preferential chirality at-metal center ( $\Lambda$ - or $\Delta$-configuration) induced by the ligand chirality. Thus, use of the enantiopure $R$ - or $S-\mathrm{N}^{\wedge} \mathrm{O}$ chelates can lead to the formation of diastereomeric pairs of $\Lambda-\mathrm{M}-R-\mathrm{N}^{\wedge} \mathrm{O}$ and $\Delta-\mathrm{M}-R-\mathrm{N}^{\wedge} \mathrm{O}$ (or $\Delta-\mathrm{M}-S-\mathrm{N}^{\wedge} \mathrm{O}$ and $\Lambda-\mathrm{M}-S-\mathrm{N}^{\wedge} \mathrm{O}$ ) in a selective way, while the racemic $R / S-\mathrm{N}^{\wedge} \mathrm{O}$ ligands give all four isomers. The non-covalent intramolecular interactions acting within the metal-chiral chelate frame lead to a free-energy difference between the diastereomers, resulting in one diastereomer being predominant both in solution and in the solid state. ${ }^{6-7,12,18-20,22,24,29,30}$ While the diastereoselection occurs quantitatively in the solid state, in solution both $\Lambda$ and $\Delta$ diastereomers exist with the preferred formation of one. Our previous results demonstrate that the induced chirality at-metal centre can be efficiently controlled by the ligand chirality, selection of metal ion and solute-solvent interactions. $^{12,18-20,22,24}$ The mechanism of diastereoselection is well studied for octahedral or five-coordinated complexes, ${ }^{30}$ but little attention has been paid to four-coordinated, asymmetric complexes. For these latter, the $\Delta$ or $\Lambda$-configuration can be interconverted by ligand exchange or by rearrangement through a planar geometry.

Because the diastereomeric equilibrium is likely to change upon dissolution of the crystalline complex, different methods are necessary to study the diastereoselection phenomenon both in the solid state and in solution. X-ray crystallography is a straight-forward method for determining the metal-centered absolute configuration. ${ }^{12,20,22,24,31,32}$ Solid state structure, however, does not necessarily represent the thermodynamically most favorable geometry formed in solution or in gas phase. An inversion of absolute configuration at the metal center may even occur passing from solution to the solid state. ${ }^{12,20,24}$ Moreover, the choice of a single crystal for X-ray measurement from a diastereomeric crystal mixture, which contains one major diastereomer, does not exclude the existence of a minor diastereomer in the mixture. An alternative analysis in the solid state is possible by Differential Scanning Calorimetry (DSC), in which thermally induced structural phase transformation from crystalline (low temperature) to liquid phase (high temperature) is investigated. In principle, a solid-state mixture of two 
diastereomers $(\Delta v s . \Lambda)$ will show two distinct peaks during transformation, one corresponding to the major species, and the second one either to the eutectic mixture (if the two diastereomers occur in the same crystal) or to the minor species (if a diastereomeric crystal mixture occurs, i.e. the two diasteromers crystallize separately). ${ }^{33}$

NMR spectroscopy in solution has successfully been used to study $\Delta$ vs. $\Lambda$ equilibrium quantitatively, based on different signals associated to the $\Delta$ or $\Lambda$ diastereomer and their integration values, and to provide the diastereomeric ratio as a function of variable time and temperature. The main drawback of this technique is the impossibility of assigning the absolute configuration for each diastereomer in a direct way (i.e., which peaks correspond to $\Delta$ or $\Lambda$ ) and the fact it is unusable for paramagnetic substances. The first problem may be solved by using NMR in combination with a chiroptical technique such ECD and VCD, with the support of theoretical analyses. ${ }^{12,20,22,24,34}$

We report herein the results of syntheses, spectroscopy, ECD spectra and X-ray structures of $\Lambda$ or $\Delta$-bis $\left[\left\{(R\right.\right.$ or $S)-\mathrm{N}$-(Ar)ethyl-2-oxo-1-naphthaldiminato- $\left.\left.\kappa^{2} \mathrm{~N}, \mathrm{O}\right\}\right]$ zinc(II). X-ray analyses show the tetrahedral geometry with induced chirality at zinc(II). The $R$ - or $S$-ligand configuration induces diastereoselectively the $\Lambda$ - or $\Delta$-metal configuration at solid state, while a dynamic diastereomeric equilibrium $(\Lambda$ vs. $\Delta)$ occurs in solution. Variable time and temperature dependent ${ }^{1} \mathrm{H}$ NMR technique is employed to study the diastereomeric equilibrium. ECD spectra, including variable temperature ones in combination with TDDFT calculations confirm the occurrence of a marked diastereoselection. Very interestingly, the ECD spectra of the present $\mathrm{Zn}$ compounds show an exciton couplet in the long wavelength region whose sign contradicts the expectation of the exciton chirality rule, unless the exciton coupling potential is quantitatively evaluated using transition densities.

\section{RESULTS AND DISCUSSION}

Reactions of enantiopure ( $R$ or $S$ )-N-1-(Ar)ethyl-2-oxo-1-naphthaldimine with zinc(II)acetate provides the $\Lambda / \Delta$ or $\Delta / \Lambda$-bis $\left[\left\{(R\right.\right.$ or $S)$-N-(Ar)ethyl-2-oxo-1-naphthaldiminato- $\left.\left.\kappa^{2} \mathrm{~N}, \mathrm{O}\right\}\right]$ zinc(II) complexes (Scheme 1). ESI mass spectra show the parent ion at $m / z 613(\Delta / \Lambda-\mathrm{Zn}-1 S$ or $\Lambda / \Delta$ $\mathrm{Zn}-1 R)$ and $673(\Delta / \Lambda-\mathrm{Zn}-2 S$ or $\Lambda / \Delta-\mathrm{Zn}-2 R)$ for $[\mathrm{M}+\mathrm{H}]^{+}$, and several peaks for the ligands. Vibrational spectra show the main characteristic bands at $c a .1616,1603$ and $1586 \mathrm{~cm}^{-1}(\mathrm{vC}=\mathrm{N})$ for the imine group of Schiff base ligands coordinated to the metal ion. 

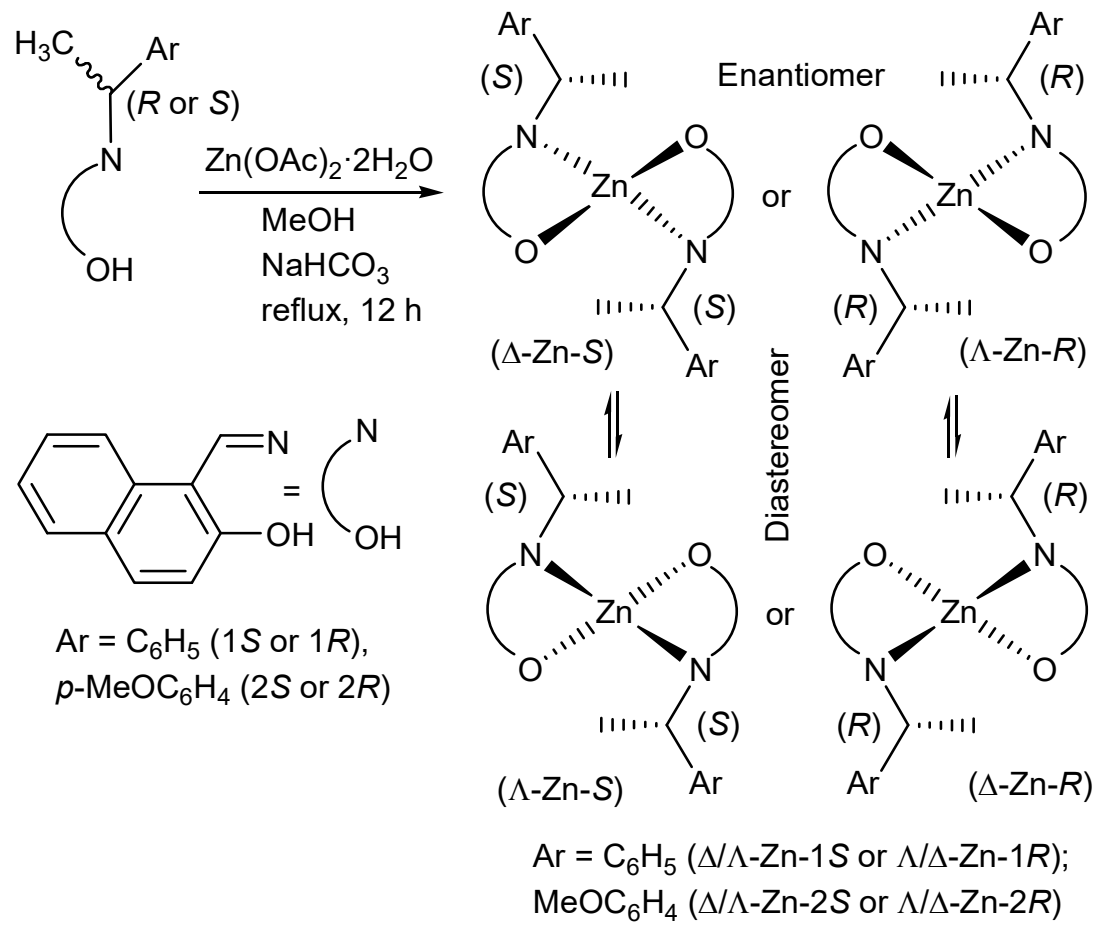

$\mathrm{Ar}=\mathrm{C}_{6} \mathrm{H}_{5}(1 \mathrm{~S}$ or $1 R)$,

$p-\mathrm{MeOC}_{6} \mathrm{H}_{4}(2 \mathrm{~S}$ or $2 R)$

Scheme 1. Synthetic route to the formulation of $\Delta / \Lambda$ - or $\Lambda / \Delta-b i s[\{(R$ or $S)-N-($ Ar)ethyl-2-oxo1-naphthaldiminato- $\left.\kappa^{2} \mathrm{~N}, \mathrm{O}\right\}$ ]zinc(II).

\section{Thermally induced structural phase transformation.}

Transition metal- $N, O$-chelate complexes exhibit thermally induced structural phase transformation from low temperature crystalline phase (distorted tetrahedral/square planar) to high temperature isotropic liquid phase (regular tetrahedral/square planar). ${ }^{7 \mathrm{a}-\mathrm{d}, 19-24,35,36}$ Differential Scanning Calorimetry (DSC) has been used to analyze the phenomenon. Thus, DSC heating and cooling curves (first cycle) show both exothermic and endothermic peaks at 173-178 and $125-127{ }^{\circ} \mathrm{C}$, respectively for $\mathrm{Zn}-1 R$ or $\mathrm{Zn}-1 S$ (Figure 1 and Table 1). DSC analyses repeated for second cycle reproduce the identical peaks, respectively. This result strongly indicates a reversible phase transformation from crystalline phase to isotropic liquid phase. Additionally, the first heating curves show weak broad peaks below $c a .100{ }^{\circ} \mathrm{C}$ due to the presence of a small amount of free ligand and solvent in the sample, which decompose on further heating, so that the peaks disappear in the second cycle. The presence of a single peak (both for heating and cooling) is an indication of a single diastereomer of $\Lambda$-Zn- $1 R$ or $\Delta-\mathrm{Zn}-1 S$ in the solid state, in line with X-ray analyses.

The DSC heating curve for $\mathrm{Zn}-2 S$ or $\mathrm{Zn}-2 R$ shows two exothermic peaks at $c a .140{ }^{\circ} \mathrm{C}$ (major peak) and $149^{\circ} \mathrm{C}$ (minor peak) in each case, while cooling curves show no corresponding peaks on the reverse direction (Figure 1 and Table 1). In fact, the heating curve in the second cycle also shows no peaks, indicative of an irreversible phase transformation. We assign the two 
peaks on heating to the presence of two diastereomers $(\Delta v s . \Lambda)$ in the solid state, in agreement with ${ }^{1} \mathrm{H}$ NMR studies in solution, discussed below. Solid-state X-ray structures for Zn- $2 S$ and $\mathrm{Zn}-2 R$ show the presence of a single chiral-at-metal configuration in each case, namely $\Delta-\mathrm{Zn}$ $2 S$ and $\Lambda-Z n-2 R$. We assume, however, that both the $\Delta$ - and $\Lambda$-diastereomers crystallized in separate crystals in each case, albeit not in equal amounts, for the zinc complex of ligand 2, and that $\Delta-\mathrm{Zn}-2 S$ and $\Lambda-\mathrm{Zn}-2 R$ are the major diastereomers and correspond to the major peaks observed in the DSC. Thus, the remaining minor peaks correspond to the minor $\Lambda-Z n-2 S$ and $\Delta$ $\mathrm{Zn}-2 R$ diastereomers, respectively. The diastereomeric ratios (\%), calculated from the heat change $\left(\Delta \mathrm{H} / \mathrm{kJ} \mathrm{mol}^{-1}\right)$ of the corresponding peaks (Table 1), assuming the molar enthalpies to be similar for the two diasteromers, are $81 / 19(\%)$ for $\Delta / \Lambda-Z n-2 S$ and $85 / 15(\%)$ for $\Lambda / \Delta-Z n-2 R$, comparable to the results obtained in ${ }^{1} \mathrm{H}$ NMR studies (i.e., $83 / 17$ for $\Delta / \Lambda$-Zn- $2 S$ or $\Lambda / \Delta$-Zn- $2 R$ ) (vide infra).
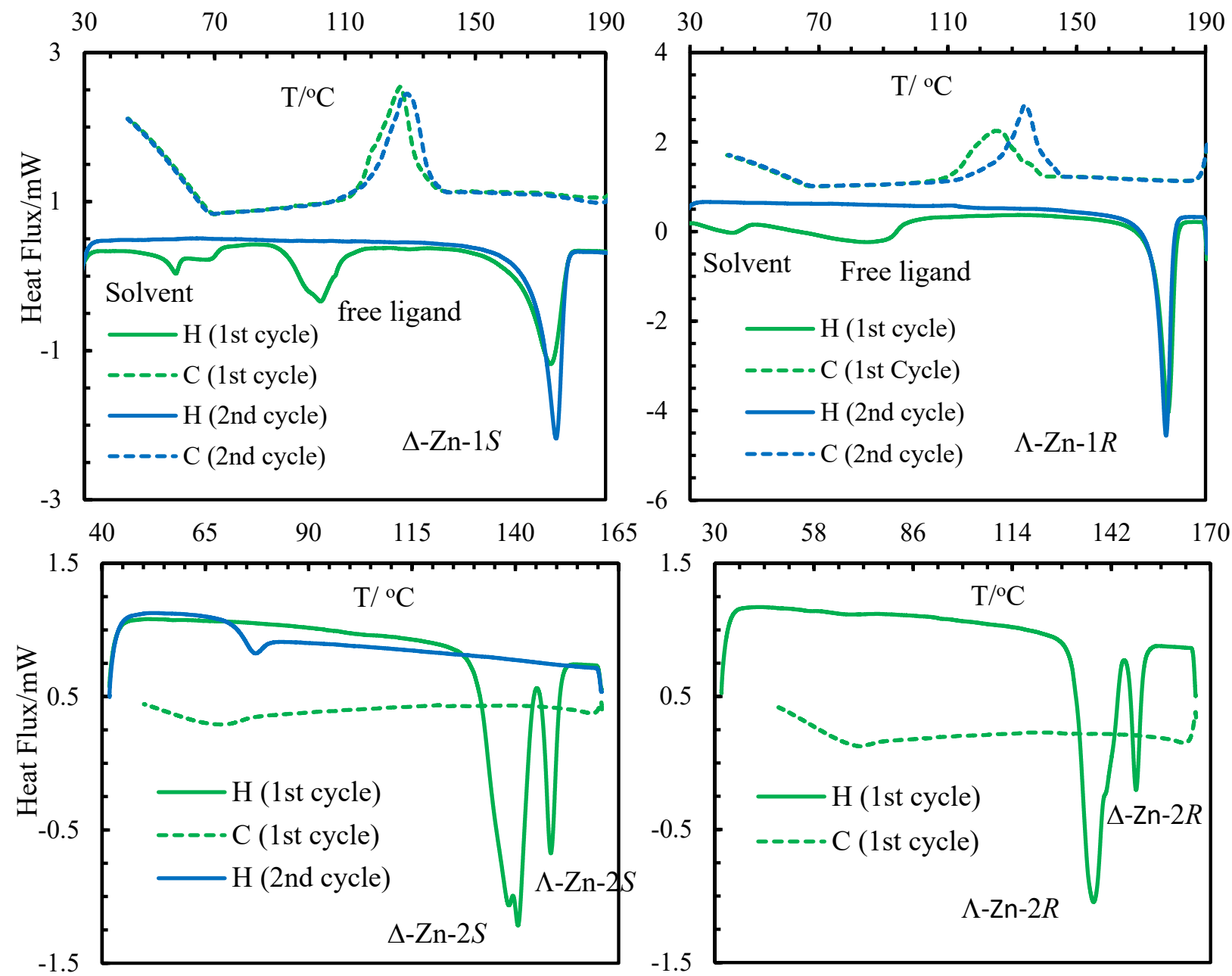

Figure 1. Differential scanning calorimetry (DSC) curves for $\Delta-\mathrm{Zn}-1 S, \Lambda$-Zn-1R (top) and $\Delta / \Lambda$ Zn-2S, $\Lambda / \Delta-Z n-2 R$ (bottom) $(\mathrm{H}=$ heating, $\mathrm{C}=$ cooling). 
Table 1. Differential scanning calorimetry (DSC) data for the compounds.

\begin{tabular}{|c|c|c|c|}
\hline Entity & $\begin{array}{c}\text { Peaks }\left({ }^{\circ} \mathrm{C}\right) / \Delta \mathrm{H}\left(\mathrm{kJ} \mathrm{mol}^{-1}\right) \\
(\text { Heating curve })\end{array}$ & $\begin{array}{l}\text { Diastereomeric } \\
\quad \text { ratio }(\%)^{\#}\end{array}$ & $\begin{array}{c}\text { Peaks }\left({ }^{\circ} \mathrm{C}\right) / \Delta \mathrm{H}\left(\mathrm{kJ} \mathrm{mol}^{-1}\right) \\
(\text { Cooling curve })\end{array}$ \\
\hline$\Delta-\mathrm{Zn}-1 S$ & $\begin{array}{l}173 /-20.51 \text { ( } 1 \text { st cycle }) \\
175 /-23.46(2 \text { nd cycle })\end{array}$ & $100(\Delta)$ & $\begin{array}{l}127 /+21.47(1 \text { st cycle }) \\
129 /+22.20(2 \text { nd cycle })\end{array}$ \\
\hline$\Lambda-\mathrm{Zn}-1 R$ & $\begin{array}{l}178 /-27.74(1 \text { st cycle }) \\
178 /-28.21(2 \text { nd cycle })\end{array}$ & $100(\Lambda)$ & $\begin{array}{l}125 /+22.14(1 \text { st cycle }) \\
134 /+23.32(2 \text { nd cycle })\end{array}$ \\
\hline$\Delta / \Lambda-Z n-2 S$ & $\begin{array}{c}141 /-19.12,149 /-4.48 \text { ( } 1 \text { st cycle) } \\
\text { no peak ( } 2 \text { nd cycle) }\end{array}$ & $\begin{array}{c}81 / 19(\Delta / \Lambda) \\
-\end{array}$ & $\begin{array}{l}\text { no peak ( } 1 \text { st cycle) } \\
\text { no peak ( } 2 \text { nd cycle) }\end{array}$ \\
\hline$\Lambda / \Delta-\mathrm{Zn}-2 R$ & $\begin{array}{c}137 /-21.76,149 /-3.90 \text { ( } 1 \text { st cycle) } \\
\text { no peak ( } 2 \text { nd cycle })\end{array}$ & $85 / 15(\Lambda / \Delta)$ & $\begin{array}{l}\text { no peak ( } 1 \text { st cycle) } \\
\text { no peak ( } 2 \text { nd cycle) }\end{array}$ \\
\hline
\end{tabular}

\# Diastereomeric ratio (\%) calculated from the heat change of corresponding peaks for 1 st heating cycle.

\section{Solid state structural studies.}

The zinc atoms in the complexes synthesized here with the deprotonated Schiff base ligands $(1 R / S$ or $2 R / S)$ have a four co-ordinate structure as evidenced by single crystal X-ray determination of the enantiomeric pairs $\Lambda-\mathrm{Zn}-1 R, \Delta-\mathrm{Zn}-1 S$ and $\Lambda-\mathrm{Zn}-2 R, \Delta-\mathrm{Zn}-2 S$. Two $\mathrm{N}^{\wedge} \mathrm{O}-$ chelate ligands form a near tetrahedral $\mathrm{N}_{2} \mathrm{O}_{2}$-coordination sphere around the zinc atom (Figure 2). The two ligands are crystallographically independent, the zinc atom sits on a general position. Still, the ligands exhibit an approximately $\mathrm{C}_{2}$-symmetric arrangement (cf. Scheme 1) with the assumed $\mathrm{C}_{2}$-axis dissecting the $\mathrm{O}-\mathrm{Zn}-\mathrm{O}$ and the $\mathrm{N}-\mathrm{Zn}-\mathrm{N}$ angles. Bond lengths and angles are listed in Table 2 and are comparable to those from literature for analogous $\mathrm{Zn}(\mathrm{II})$ N,O-chelate Schiff base complexes. ${ }^{6 a, c,-12 a}$ From the aromatic rings in the complexes there are no detectable $\pi-\pi$ interactions ${ }^{31}$ but intermolecular $\mathrm{C}-\mathrm{H} \cdots \pi$ contacts $^{37}$ and $\mathrm{C}-\mathrm{H} \cdots \mathrm{O}$ interaction; a detailed analysis is reported in the Supporting Information.

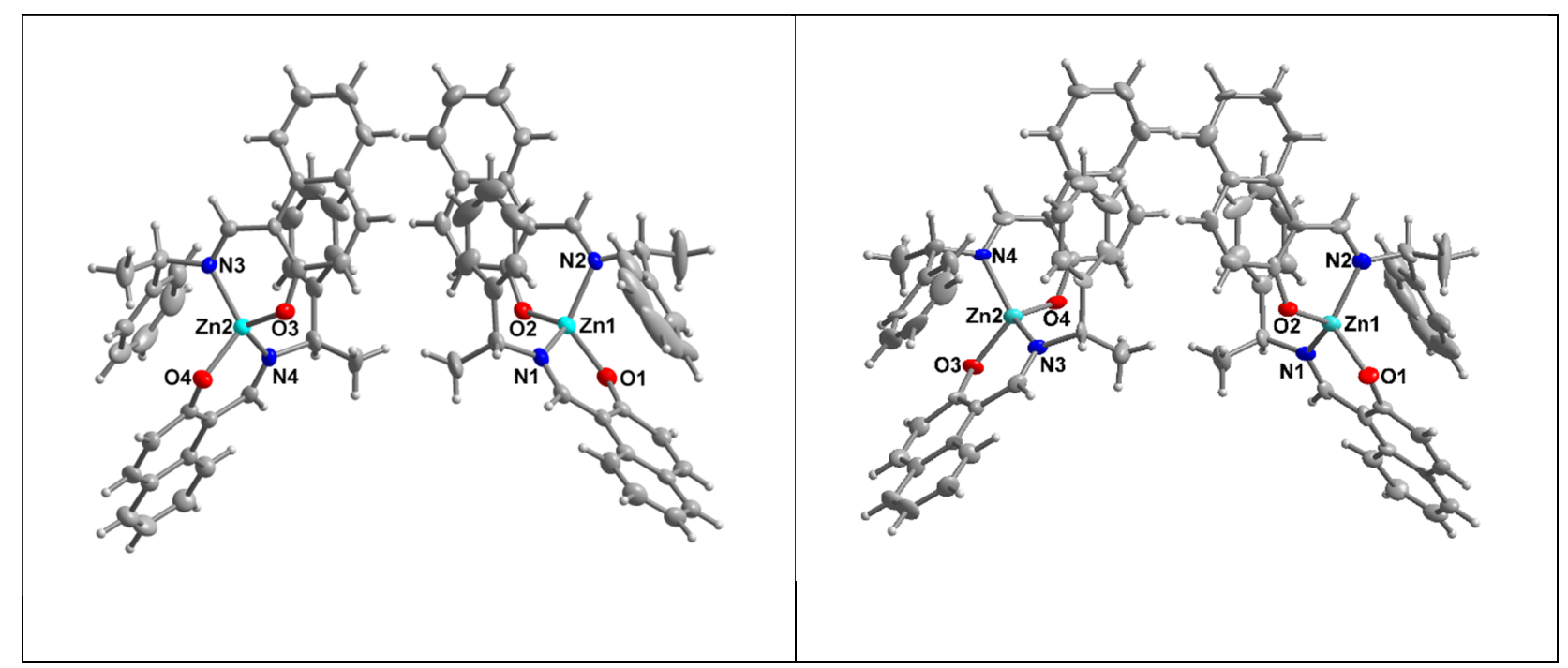




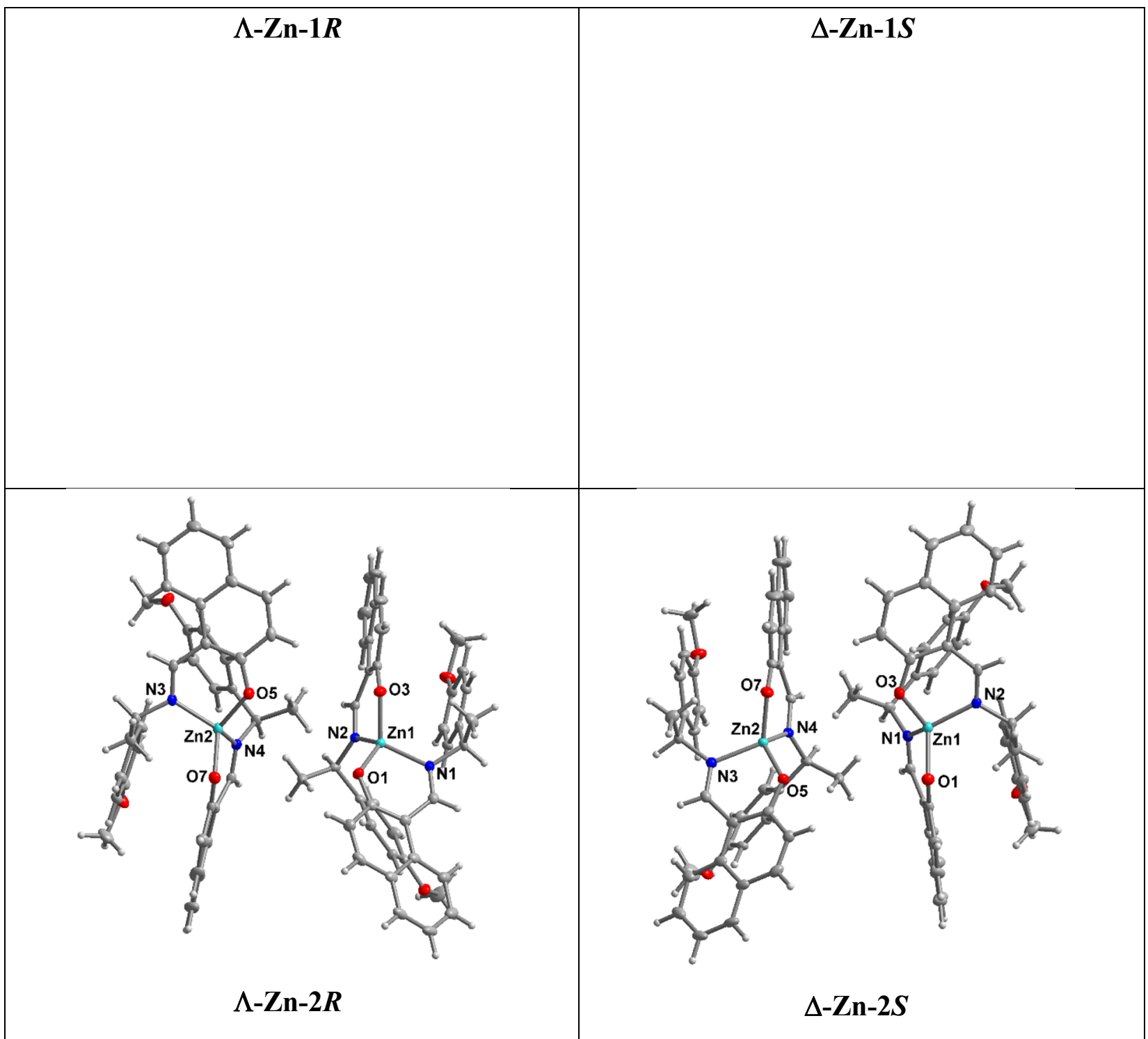

Figure 2. Two symmetry-independent molecules in the asymmetric unit in compounds $\Lambda$-Zn$1 R, \Delta-\mathrm{Zn}-1 S, \Lambda$-Zn-2R and $\Delta-\mathrm{Zn}-2 S$ (50\% thermal ellipsoids). See Table 2 for bond lengths and angles.

Table 2. Selected bond lengths $(\AA)$ and angles $\left(^{\circ}\right)$ of the compounds.

\begin{tabular}{|c|c|c|c|c|c|c|c|}
\hline \multicolumn{4}{|c|}{$\Lambda-\mathrm{Zn}-1 R$} & \multicolumn{4}{|c|}{$\Delta-\mathrm{Zn}-1 S$} \\
\hline \multicolumn{4}{|c|}{ Molecule A } & \multicolumn{4}{|c|}{ Molecule A } \\
\hline $\mathrm{Zn} 1-01$ & $1.927(4)$ & $01-\mathrm{Zn} 1-02$ & $110.27(16)$ & Zn1-O1 & $1.917(9)$ & $01-\mathrm{Zn} 1-02$ & $109.6(4)$ \\
\hline $\mathrm{Zn} 1-\mathrm{O} 2$ & $1.926(3)$ & $\mathrm{O} 1-\mathrm{Zn} 1-\mathrm{N} 2$ & $117.46(17)$ & $\mathrm{Zn} 1-\mathrm{O} 2$ & $1.918(9)$ & O1-Zn1-N2 & $117.2(4)$ \\
\hline $\mathrm{Zn} 1-\mathrm{N} 2$ & $1.992(4)$ & $\mathrm{O} 2-\mathrm{Zn} 1-\mathrm{N} 2$ & $93.96(16)$ & $\mathrm{Zn} 1-\mathrm{N} 2$ & $1.989(9)$ & $\mathrm{O} 2-\mathrm{Zn} 1-\mathrm{N} 2$ & $95.1(4)$ \\
\hline \multirow[t]{3}{*}{ Zn1-N1 } & $1.998(4)$ & O1-Zn1-N1 & $94.56(15)$ & Zn1-N1 & $1.970(1)$ & O1-Zn1-N1 & $94.5(4)$ \\
\hline & & $\mathrm{O} 2-\mathrm{Zn} 1-\mathrm{N} 1$ & $117.53(16)$ & & & $\mathrm{O} 2-\mathrm{Zn} 1-\mathrm{N} 1$ & $117.2(4)$ \\
\hline & & $\mathrm{N} 2-\mathrm{Zn} 1-\mathrm{N} 1$ & $124.09(17)$ & & & $\mathrm{N} 2-\mathrm{Zn} 1-\mathrm{N} 1$ & $124.1(4)$ \\
\hline \multicolumn{4}{|c|}{ Molecule B } & \multicolumn{4}{|c|}{ Molecule B } \\
\hline $\mathrm{Zn} 2-\mathrm{O} 4$ & $1.926(4)$ & $\mathrm{O} 4-\mathrm{Zn} 2-\mathrm{O} 3$ & $116.87(16)$ & $\mathrm{Zn} 2-04$ & $1.910(1)$ & $\mathrm{O} 4-\mathrm{Zn} 2-\mathrm{O} 3$ & $110.9(4)$ \\
\hline $\mathrm{Zn} 2-\mathrm{O} 3$ & $1.913(4)$ & $\mathrm{O} 4-\mathrm{Zn} 2-\mathrm{N} 4$ & $95.94(16)$ & $\mathrm{Zn} 2-\mathrm{O} 3$ & $1.916(7)$ & $\mathrm{O} 4-\mathrm{Zn} 2-\mathrm{N} 4$ & $94.6(4)$ \\
\hline $\mathrm{Zn} 2-\mathrm{N} 4$ & $1.977(4)$ & $\mathrm{O} 3-\mathrm{Zn} 2-\mathrm{N} 4$ & $110.83(16)$ & $\mathrm{Zn} 2-\mathrm{N} 4$ & $1.990(1)$ & $\mathrm{O} 3-\mathrm{Zn} 2-\mathrm{N} 4$ & $113.3(4)$ \\
\hline $\mathrm{Zn} 2-\mathrm{N} 3$ & $1.991(4)$ & $\mathrm{O} 4-\mathrm{Zn} 2-\mathrm{N} 3$ & $113.27(17)$ & $\mathrm{Zn} 2-\mathrm{N} 3$ & $1.960(1)$ & $\mathrm{O} 4-\mathrm{Zn} 2-\mathrm{N} 3$ & $116.8(4)$ \\
\hline
\end{tabular}




\begin{tabular}{|c|c|c|c|c|c|c|c|}
\hline & & $\mathrm{O} 3-\mathrm{Zn} 2-\mathrm{N} 3$ & $94.54(17)$ & & & $\mathrm{O} 3-\mathrm{Zn} 2-\mathrm{N} 3$ & $95.4(4)$ \\
\hline & & $\mathrm{N} 4-\mathrm{Zn} 2-\mathrm{N} 3$ & $126.00(17)$ & & & $\mathrm{N} 4-\mathrm{Zn} 2-\mathrm{N} 3$ & $126.5(4)$ \\
\hline \multicolumn{4}{|c|}{$\Lambda-\mathrm{Zn}-2 R$} & \multicolumn{4}{|c|}{$\Delta-\mathrm{Zn}-2 S$} \\
\hline \multicolumn{4}{|c|}{ Molecule A } & \multicolumn{4}{|c|}{ Molecule A } \\
\hline $\mathrm{Zn} 1-03$ & $1.926(2)$ & O3-Zn1-O1 & $113.09(6)$ & Zn1-01 & $1.934(2)$ & O1-Zn1-O3 & $117.71(7)$ \\
\hline $\mathrm{Zn} 1-01$ & $1.943(2)$ & $\mathrm{O} 3-\mathrm{Zn} 1-\mathrm{N} 1$ & 113.19(7) & Zn1-03 & $1.935(2)$ & O1-Zn1-N2 & $111.53(7)$ \\
\hline $\mathrm{Zn} 1-\mathrm{N} 1$ & 1.991(3) & O1-Zn1-N1 & $92.90(6)$ & Zn1-N2 & 1.996(3) & O3-Zn1-N2 & $93.62(7)$ \\
\hline \multirow[t]{3}{*}{$\mathrm{Zn} 1-\mathrm{N} 2$} & $1.996(2)$ & O3-Zn1-N2 & $95.51(7)$ & Zn1-N1 & $2.004(2)$ & O1-Zn1-N1 & $95.57(7)$ \\
\hline & & $\mathrm{O} 1-\mathrm{Zn} 1-\mathrm{N} 2$ & $119.46(7)$ & & & $\mathrm{O} 3-\mathrm{Zn} 1-\mathrm{N} 1$ & $114.89(7)$ \\
\hline & & $\mathrm{N} 1-\mathrm{Zn} 1-\mathrm{N} 2$ & $123.93(7)$ & & & $\mathrm{N} 2-\mathrm{Zn} 1-\mathrm{N} 1$ & $125.37(7)$ \\
\hline \multicolumn{4}{|c|}{ Molecule B } & \multicolumn{4}{|c|}{ Molecule B } \\
\hline $\mathrm{Zn} 2-07$ & $1.933(2)$ & $07-Z n 2-05$ & $117.74(6)$ & Zn2-07 & $1.929(2)$ & $07-Z n 2-05$ & $113.10(7)$ \\
\hline Zn2-05 & $1.938(2)$ & O7-Zn2-N3 & $111.68(6)$ & Zn2-05 & $1.944(2)$ & O7-Zn2-N4 & $95.50(7)$ \\
\hline Zn2-N3 & $1.997(3)$ & O5-Zn2-N3 & $93.51(6)$ & Zn2-N4 & $1.992(2)$ & O5-Zn2-N4 & $119.49(7)$ \\
\hline \multirow[t]{3}{*}{$\mathrm{Zn} 2-\mathrm{N} 4$} & $2.008(2)$ & O7-Zn2-N4 & $95.47(6)$ & $\mathrm{Zn} 2-\mathrm{N} 3$ & 1.992(3) & O7-Zn2-N3 & $112.98(7)$ \\
\hline & & $\mathrm{O} 5-\mathrm{Zn} 2-\mathrm{N} 4$ & $115.01(7)$ & & & $\mathrm{O} 5-\mathrm{Zn} 2-\mathrm{N} 3$ & $93.02(7)$ \\
\hline & & N3-Zn2-N4 & $125.30(7)$ & & & N4-Zn2-N3 & $123.95(7)$ \\
\hline
\end{tabular}

There are two symmetry-independent molecules in the asymmetric unit of each structure, that is, a molecule A with $\mathrm{Zn} 1$ and a molecule B with $\mathrm{Zn} 2$. The structures of the analogue Nicomplexes with ligand $1 S$ or $1 R$ also contained two symmetry-independent molecules, ${ }^{24}$ as did the structures of the $\mathrm{Cu}$-complexes with ligand $2 S$ or $2 R \cdot{ }^{20}$ The $\mathrm{Zn}$ and $\mathrm{Ni}$ structures with $1 S$ or $1 R$ were pure enantiomers; both molecules in the asymmetric unit had the same metal configuration. A consistent stereochemical induction is observed here: complexation with $S$ configured ligand $1 S$ or $2 S$ leads to $\Delta$-configured zinc (that is, $\Delta-\mathrm{Zn}-1 S$ or $\Delta-\mathrm{Zn}-2 S$ ), while the corresponding $R$-ligand $1 R$ or $2 R$ affords opposite $\Lambda$-configured zinc $(\Lambda-\mathrm{Zn}-1 R$ or $\Lambda$-Zn- $2 R)$ as in the analogous $\mathrm{Cu} / \mathrm{Ni}$ (II)-complexes with the similar naphthaldiminate ligands. ${ }^{20,24}$ However, in the $\mathrm{Cu}(\mathrm{II})$-structure with $2 R$ the two symmetry-independent molecules in the asymmetric unit formed a diastereomeric pair, with $\mathrm{Cu} 1$ having $\Lambda$ - and $\mathrm{Cu} 2$ having $\Delta$-configuration. ${ }^{20}$

All four $\mathrm{Zn}$ structures given here fulfill the criterion of a Flack parameter $x$ close to zero, with standard deviation $u$ less than 0.04 and $|x| / u<3$ (vide infra) ${ }^{32}$ This criterion confirms the correct absolute structure and, together with other refinement parameters, precludes the presence of significant amounts of opposite metal configuration within the measured crystal, as found for $\Lambda-\mathrm{Zn}-1 R$ or $\Delta-\mathrm{Zn}-1 S$. However, on the basis of DSC measurements discussed above, we assume the presence of a diastereomeric crystal mixture for $\Lambda-Z n-2 R$ or $\Delta-Z n-2 S$. This could be definitely proven only by picking a crystal belonging to the opposite diastereomer, for example $\Delta-\mathrm{Zn}-2 R$ or $\Lambda-\mathrm{Zn}-2 S$, which, according to the proportions measured by DSC, is an unlikely event. 
Two symmetry-independent molecules, that is, two identical chemical formula units in the structural asymmetric unit ${ }^{38}$ give a $Z^{\prime}=2$ structure. The definition of $Z^{\prime}$ refers to the number of formula units in the unit cell (here 2 in $\Lambda-Z n-1 R$ or $\Delta-\mathrm{Zn}-1 S$ and 4 in $\Lambda$-Zn-2R or $\Delta-\mathrm{Zn}-2 S$ ) divided by the number of independent general positions (here 1 and 2 , respectively). ${ }^{39}$ Such $Z^{\prime}$ $>1$ structures $^{40}$ can derive from a metastable structure, that is, a crystal "on the way", $38-40,41$ or from strong and special supramolecular (e.g. hydrogen bonding) interactions between the two (or more) symmetry-independent units. $^{42}$ A molecule with different equi-energetic conformations also gives a high Z' such that these conformations co-exist in the crystal. ${ }^{43}$ The probability for $Z^{\prime}>1$ is higher in non-centrosymmetric space groups with (enantiopure) chiral molecules which cannot pack efficiently in the absence of centrosymmetry. ${ }^{44 a}$

In the recent $\mathrm{Ni}$ structures of $1 R$ or $1 S$ ligands with two symmetry independent molecules in the asymmetric unit the two bidentate $N^{\wedge} O$-chelate Schiff base ligands co-ordinated to the nickel atom in a distorted square planar $\mathrm{N}_{2} \mathrm{O}_{2}$-coordination sphere. The conformational difference between the symmetry-independent molecules arose from "up-or-down" folding of the naphthaldiminato ligand with respect to the coordination plane, which created right- $(P)$ or left-handed $(M)$ helical conformations. Overall, the combination of ligand chirality, chirality at metal and ligand folding gave rise to discrete metal helicates of preferred helicity in a selective way. $^{24}$

Here, in the $\mathrm{Zn}$ structures the conformational difference between the symmetry-independent molecules is nearly insignificant. The two symmetry-independent molecules are quite superimposable (Figure 3). Neither these very small deviations nor the rather weak supramolecular interactions (see listing of $\mathrm{CH}-\pi$ and $\mathrm{CH}-\mathrm{O}$ interactions in Supporting Information with Figures S2-S4) appear to justify the presence of two symmetry-independent molecules.
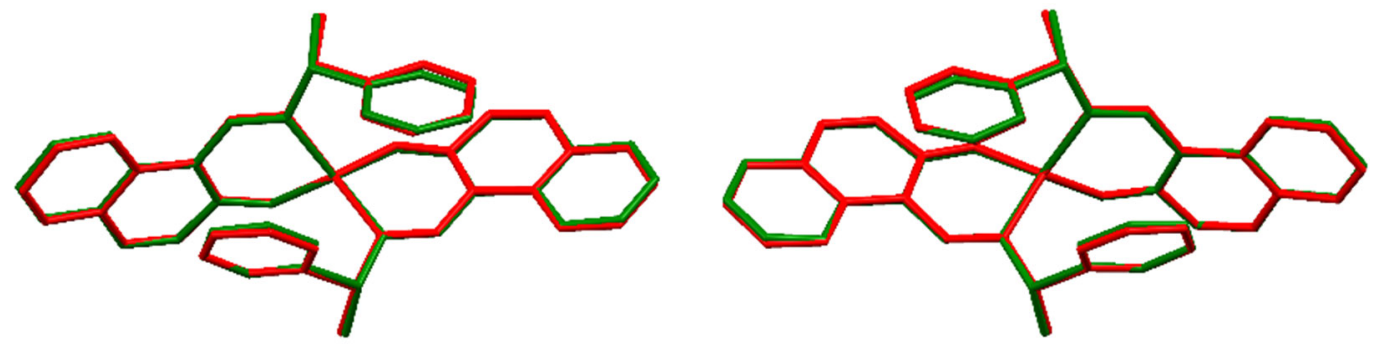

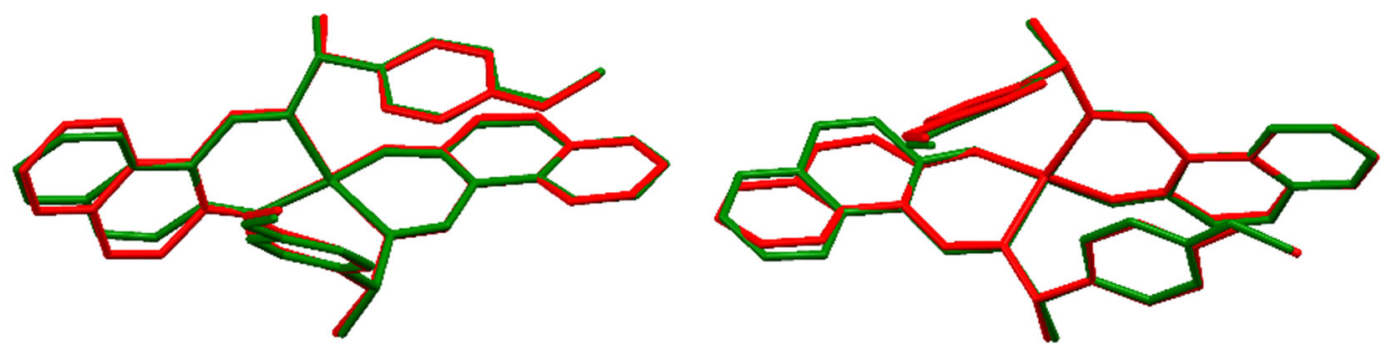

Figure 3. Overlay of the two symmetry independent molecules in $\Lambda$-Zn- $1 R$ (top-left), $\Delta-Z n-1 S$ (top-right), $\Lambda$-Zn-2R (bottom-left) and $\Delta-\mathrm{Zn}-2 S$ (bottom-right). The $\mathrm{Zn} 1$ molecules are shown in green, the $\mathrm{Zn} 2$ molecules in red (hydrogen atoms omitted for clarity). The five atoms $\mathrm{ZnN}_{2} \mathrm{O}_{2}$ were specified to orient the overlay which was managed with the "Molecule overlay" option in Mercury 3.5.1 (copyright CCDC 2001-2014, http://www.ccdc.cam.ac.uk/mercury/).

Thus, the rationalization of the $Z^{\prime}=2$ structure must be sought for in the packing arrangement. Each independent molecule in $\Delta-\mathrm{Zn}-1 S$ and $\Lambda-\mathrm{Zn}-2 R$ is arranged in layers composed of molecules of the same kind (Figure 4, top). These layers lie parallel to the $a b$ plane and stack alternately for the independent molecules along the $c$ direction. A closer inspection of the orientation of the independent molecules with respect to each other, seems to suggest a (missing) symmetry relation between them at first sight (Figure 4, bottom). Careful examination of the atomic coordinates (e.g. Zn coordinates given in Figure 4, bottom) shows that this is merely a pseudo-symmetry element. Therefore, we suggest that the van-der-Waals surface of the molecules does not allow for a symmetry-related packing along the $c$ axis in the absence of centrosymmetry.
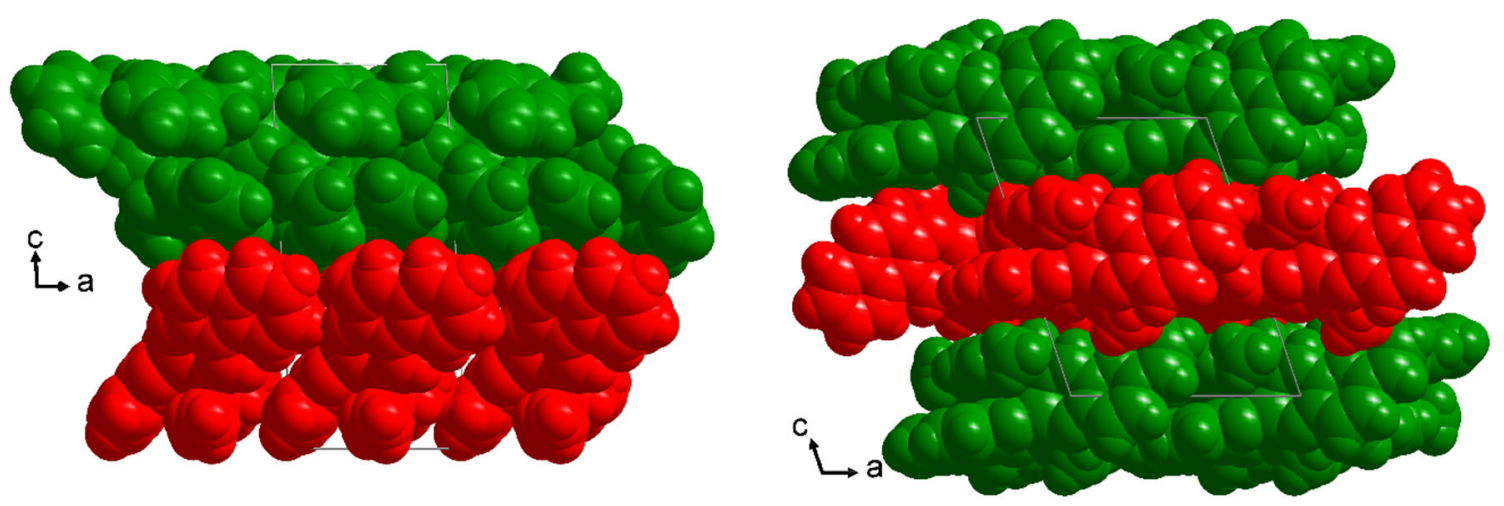

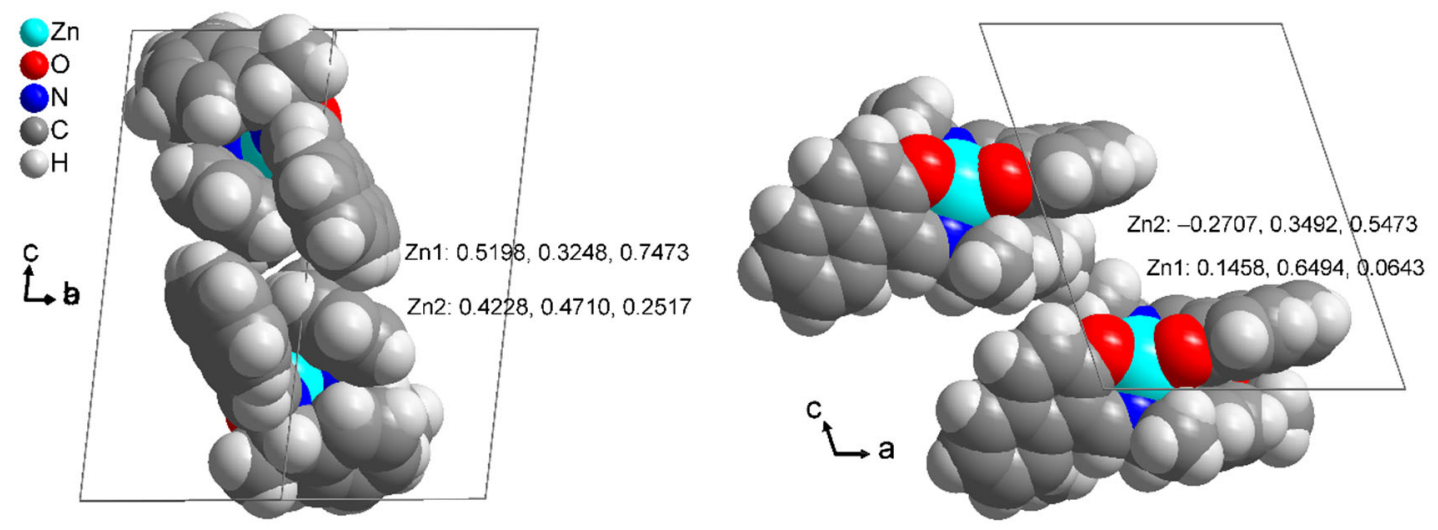

Figure 4. Top row: Packing diagrams for $\Delta-\mathrm{Zn}-1 S$ (left) and $\Lambda-\mathrm{Zn}-2 R$ (right) with the molecules depicted in space filling mode. The Zn1 molecules are shown in green, the Zn2 molecules in red. Bottom row: Two selected molecules - one each for the independent units in $\Delta-\mathrm{Zn}-1 S$ (left) and $\Lambda$-Zn-2R (right) where, by visual inspection, a pseudo-symmetry relationship seems apparent, such as a twofold axis in $\Delta$-Zn- $1 S$ (left) or a glide plane in $\Lambda$-Zn$2 R$ (right). Comparison of the $\mathrm{Zn} 1$ and $\mathrm{Zn} 2$ coordinates excludes a real symmetry element.

For more quantitative analysis of the coordination geometry, also in comparison with DFT results discussed in the following, the degree of distortion from tetrahedral to square-planar can be expressed by the dihedral angle $\theta$ between the two planes formed by the donor atoms with the metal atom, that is, N1-M-O1 and N2-M-O2 (Table 3). ${ }^{12,20-24}$ The dihedral angle $\theta$ is $90^{\circ}$ for tetrahedral and $0^{\circ}$ for square-planar geometry (not considering the inherent distortion induced by the chelate ring formation). ${ }^{36 a}$ In addition, $\theta$ can be normalized to give the geometric index $\tau_{\text {tet-sq }}$ (Scheme 2), whose values vary from 1.0 (regular tetrahedral) to zero (regular square-planar). ${ }^{12,20-24}$ Also, a geometry index $\tau_{4}$ for four-coordinate complexes with $\tau_{4}=\left[360^{\circ}-(\alpha+\beta)\right] / 141^{\circ}$ has been proposed, akin to Addison and Reedijk's five-coordinate $\tau_{5}$ index, with $\alpha$ and $\beta$ being the two largest angles in the four-coordinate species. The values of $\tau_{4}$ will be 1.00 for a perfect tetrahedral geometry, since $360-2(109.5)=141$, and zero for a perfect square planar geometry, since 360 $-2(180)=0 .{ }^{36}$ The values of $\theta$ and the geometric indices (i.e., measures of distortion) listed in Table 3 demonstrate that the coordination geometry of the present zinc(II)-complexes are very near to a regular tetrahedron . 


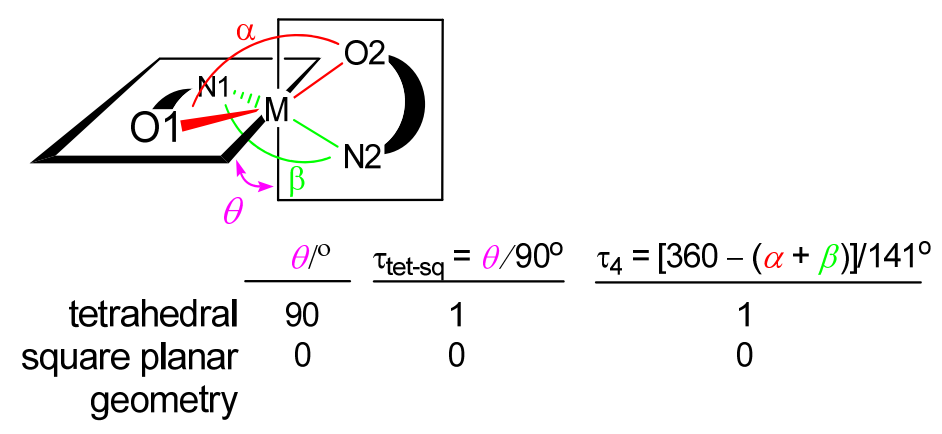

Scheme 2. Assessments of distortions from tetrahedral by $\theta, \tau_{\text {tet-sq }}$ and $\tau_{4}$, respectively (where $\alpha$ and $\beta$ are the two largest angles in the four-coordinated species). For two chelate ligands, as in bis-bidentate Schiff base complexes, the dihedral angle $\theta$ or its normalized index $\tau_{\text {tet-sq }}=\theta / 90^{\circ}$ is preferred. The index $\tau_{4}$ will not correctly assess a tetrahedral geometry because of the already present distortion due to the chelate ring formation. With chelate ligands the two largest angles will already be larger than $109.5^{\circ}$, hence, $\tau_{4}<1$, even if the dihedral planes are perfectly perpendicular.

Table 3. Measurements of distortions from tetrahedral geometry.

\begin{tabular}{|c|c|c|c|c|c|}
\hline Compound & Molecule & $\theta /{ }^{\circ} a$ & $\begin{array}{c}\theta^{\circ}{ }^{\circ} \\
\text { calc. }{ }^{b}\end{array}$ & $\tau_{\text {tet-sq }}=\theta / 90^{\circ} c$ & $\tau_{4}{ }^{d}$ \\
\hline \multirow[t]{2}{*}{$\Lambda-Z n-1 R$} & A & $\begin{array}{c}88.89(\mathrm{Zn} 1) \\
(\mathrm{N} 1 Z n 1 \mathrm{O} 1 \& \mathrm{~N} 2 \mathrm{Zn} 1 \mathrm{O} 2)\end{array}$ & \multirow{2}{*}{-} & 0.99 & 0.83 \\
\hline & B & $\begin{array}{c}88.24(\mathrm{Zn} 2) \\
(\mathrm{N} 4 Z n 2 \mathrm{Z} \& \mathrm{~N} 3 \mathrm{Zn} 2 \mathrm{O} 4)\end{array}$ & & 0.98 & 0.83 \\
\hline \multirow[t]{2}{*}{$\Delta-\mathrm{Zn}-1 S$} & A & $\begin{array}{c}88.78(\mathrm{Zn} 1) \\
(\mathrm{N} 1 \mathrm{Zn} 1 \mathrm{O} 1 \text { \& N2Zn1O2) }\end{array}$ & \multirow[b]{2}{*}{ - } & 0.99 & 0.84 \\
\hline & B & $\begin{array}{c}88.03(\mathrm{Zn} 2) \\
(\mathrm{N} 4 Z n 2 \mathrm{O} \& \mathrm{~N} 3 \mathrm{Zn} 2 \mathrm{O} 4)\end{array}$ & & 0.98 & 0.83 \\
\hline \multirow[t]{2}{*}{$\Lambda-\mathrm{Zn}-2 R$} & A & $\begin{array}{c}88.54(\mathrm{Zn} 1) \\
(\mathrm{N} 1 \mathrm{Zn} 101 \text { \& N2Zn1O3) }\end{array}$ & \multirow{2}{*}{$\begin{array}{l}78.8(\Lambda) \\
73.5(\Delta)\end{array}$} & 0.98 & 0.83 \\
\hline & $\mathrm{B}$ & $\begin{array}{c}83.48(\mathrm{Zn} 2) \\
(\mathrm{N} 4 \mathrm{Zn} 2 \mathrm{O} 7 \text { \& N3Zn2O5) }\end{array}$ & & 0.93 & 0.83 \\
\hline \multirow[t]{2}{*}{$\Delta-\mathrm{Zn}-2 S$} & A & $\begin{array}{c}83.37(\mathrm{Zn} 1) \\
(\mathrm{N} 1 Z n 1 \mathrm{O} 1 \text { \& N2Zn1O3) }\end{array}$ & \multirow{2}{*}{$\begin{array}{l}78.8(\Delta) \\
73.5(\Lambda)\end{array}$} & 0.93 & 0.83 \\
\hline & B & $\begin{array}{c}88.45(\mathrm{Zn} 2) \\
\mathrm{N} 3 Z \mathrm{Zn} 2 \mathrm{O} 5 \text { \& N4Zn2O7) }\end{array}$ & & 0.98 & 0.83 \\
\hline
\end{tabular}

${ }^{a}$ See Scheme 2 for definition of $\theta ;^{\text {b }}$ by DFT geometry optimizations at the B3LYP/6-31G(d) level, lowest-energy structure (the calculated configuration at $\mathrm{Zn}$ is also given); ${ }^{\mathrm{c}} \tau_{\text {tet-sq }}=1$ for perpendicular ligand planes and near tetrahedral geometry; ${ }^{\mathrm{d}}$ See Table 2 for the two largest angles $\alpha$ and $\beta$.

Electronic absorption and ECD spectra. 
Electronic absorption and ECD spectra measured in cyclohexane for all the complexes considered are shown in Figure 5. Both the absorption and ECD spectra show consistent similarities for all complexes over the whole measured spectral range (Figure 5). The absorption spectra feature several bands with absorption maxima at ca. 240, 320, 390, $410 \mathrm{~nm}$, mainly associated with the intra-ligand $\pi \rightarrow \pi^{*}$ transitions and, at a less extent, with metal-toligand charge transfer (MLCT) transitions. ${ }^{6 \mathrm{a}, \mathrm{c}, 12 \mathrm{a}, 18}$ The complexes $\mathrm{Zn}-1 R$ and $\mathrm{Zn}-1 S$ are characterized by the following series of ECD bands indicative of $R / S$-ligand configuration at wavelengths (sign and strength): ca. $414 \mathrm{~nm}(-/+$, strong); ca. $384 \mathrm{~nm}(+/-$, strong); ca. $321 \mathrm{~nm}$ (+/-, strong); ca. 275 (+/-, medium); ca. 254 (+/-, strong); ca. $244 \mathrm{~nm}$ (-/+, weak). Similarly, $\mathrm{Zn}-2 R$ and $\mathrm{Zn}-2 S$ are characterized by the following series of ECD bands: ca. $414 \mathrm{~nm}(-/+$, strong); ca. $383 \mathrm{~nm}$ (+/-, strong); ca. $321 \mathrm{~nm}$ (+/-, strong); ca. 267 (+/-, medium); ca. $246 \mathrm{~nm}$ $(-/+$, weak). ECD spectra of the enantiomeric couples, that is, $\mathrm{Zn}-1 R$ and $\mathrm{Zn}-1 S$, and $\mathrm{Zn}-2 R$ and $\mathrm{Zn}-2 S$, show the expected mirror-image relationship in cyclohexane.

ECD spectra were also recorded in the solid state ${ }^{45 a}$ on microcrystalline samples in mixtures with an inert salt $(\mathrm{KCl}){ }^{45 b, c}$ Solid-state spectra (Supporting Information, Figure S5) are comparable with solution ones in the accessible range $(>250 \mathrm{~nm})$. In particular, three major ECD bands are detected at 418, 374 and $312 \mathrm{~nm}$ with a sequence of sign $+/-/-$ for the complex $\mathrm{Zn}-1 S$ and $-/+/+$ for $\mathrm{Zn}-1 R$, which is the same of the equivalent bands in solution (Figure 5). This finding demonstrates the correspondence between the major diastereomer found in solution and in the crystals. 

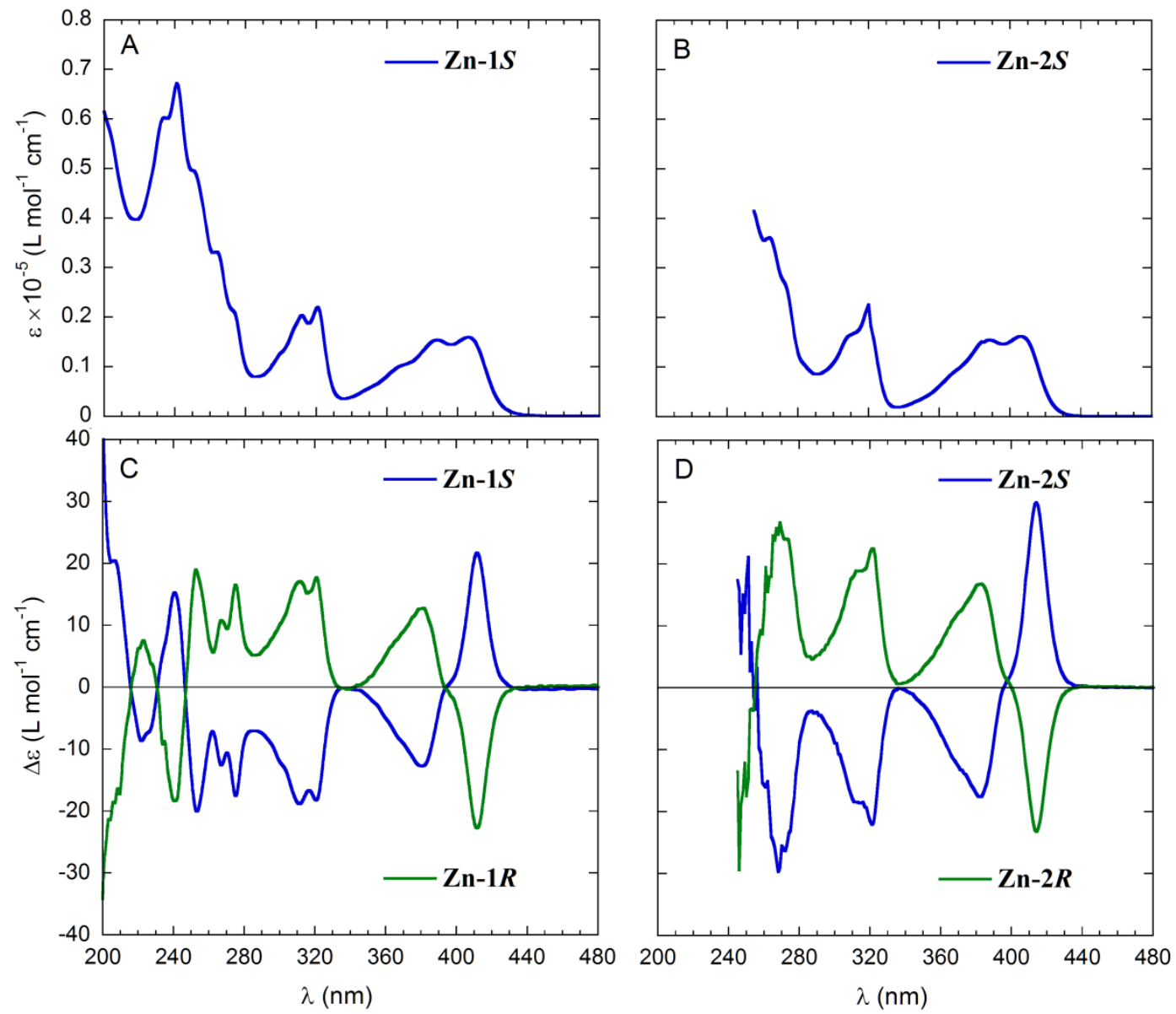

Figure 5. Experimental UV-Vis (concentration $\mathrm{Zn}-1 S: 0.86,2 S: 0.43 \mathrm{mM}$ ) and ECD spectra (Zn-1R: 1.13, Zn-1S: $0.86 \mathrm{mM}$ and Zn-2R: $0.43, \mathrm{Zn}-2 S: 0.43 \mathrm{mM})$ in cyclohexane at $20{ }^{\circ} \mathrm{C}$; cell path length $0.2(\mathrm{Zn}-1 R / S)$ and $1.0 \mathrm{~mm}(\mathrm{Zn}-2 R / S)$.

With the aim to reproduce the ECD spectra of $\mathrm{Zn}$ complexes in solution, we performed a theoretical study based on density functional theory (DFT) and time dependent DFT (TDDFT) calculations. ${ }^{44 b, c}$ As compared to the corresponding complexes of $\mathrm{Cu}$ and $\mathrm{Ni}^{20,22}$ the present case is greatly facilitated by the presence of a diamagnetic closed-shell metal. Starting from the X-ray geometry of $\Lambda-\mathrm{Zn}-2 R$, we ran a thorough conformational search with molecular mechanics and DFT geometry optimizations at B3LYP/6-31G(d) level (see Computational Section). As a result, we obtained 11 structures with relative energies within $2.5 \mathrm{kcal} / \mathrm{mol}$ and Boltzmann population $>1 \%$ at $300 \mathrm{~K}$. The various structures, shown in Figure S6-S7, differed mainly in the conformation of the $p$-methoxyphenylethyl moieties. The co-ordination geometry was tetrahedral in all cases, with angle $\theta$ between $75^{\circ}$ and $80^{\circ}$. The lowest energy structure had $\theta=78.8^{\circ}$ and $C_{2}$-symmetry, and differed from the conformation found in the crystal packing. Starting from the same complex, the configuration at the metal centre was inverted and the same conformational search/geometry optimization procedure was applied on the $\Delta-\mathrm{Zn}-2 R$ 
diastereomer. A set of 13 low-energy structures with $\Delta-Z n-2 R$ configuration was obtained with the same threshold energy and population defined above. Overall, the coordination geometry was more distorted from the ideal tetrahedron than in the previous case, for instance the first two conformers had $\theta \approx 73.5^{\circ}$. Very interestingly, the lowest-energy $\Lambda$-Zn- $2 R$ structure was more stable by $2.74 \mathrm{kcal} / \mathrm{mol}$ than the lowest-energy $\Delta-\mathrm{Zn}-2 R$ one. Thus, a clear diastereomeric preference in favour of the $\Lambda-\mathrm{Zn}-2 R$ isomer is predicted by DFT.

ECD calculations were run on the above described structures with the TDDFT method. ${ }^{44 b, c}$ After a preliminary screening of various functionals and basis sets (see Computational Section), the CAM-B3LYP/TZVP combination was chosen. The Boltzmann-average spectra calculated for $\Lambda-Z n-2 R$ and $\Delta-Z n-2 R$ (11 and 13 minima, respectively) are shown in Figure 6. Even at a first glance it appears that the ECD spectra calculated for the two diastereomeric families are almost the mirror image of each other on a wide wavelength range. This demonstrates that the ECD spectrum in solution is dominated by the metal chirality, this latter being in turn dictated by the ligand chirality. A similar phenomenon occurred for the previously investigated $\mathrm{Cu}$ and $\mathrm{Ni}$ analogues, however such consistency is not trivial at all, because the coordination geometries are very different in the three cases. ${ }^{20,22}$ Interestingly enough, the ECD spectrum calculated for $\Lambda-\mathrm{Zn}-2 R$ is in very good agreement (apart from a wavelength shift) with the experimental one for compound $\mathrm{Zn}-2 R$, which definitely demonstrates that the complex obtained from ligand $2 R$ assumes a dominant $\Lambda-Z \mathrm{n}-2 R$ configuration in solution. Because of the consistency between the experimental ECD spectra of the compounds $\mathrm{Zn}-1 R$ and $\mathrm{Zn}-2 R$, the result obtained for $\mathrm{Zn}-2 R$ may be similarly considered valid for $\mathrm{Zn}-1 R$ too.
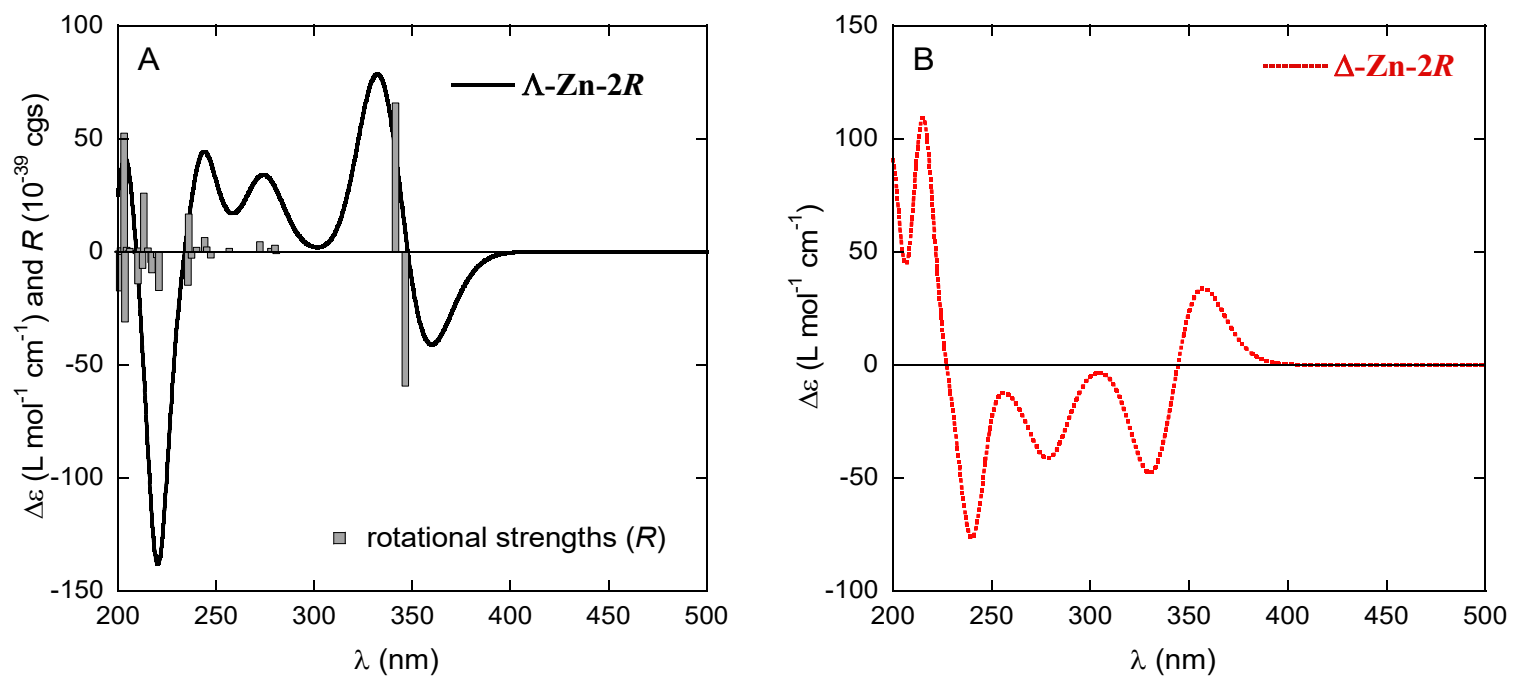

Figure 6. CD spectra calculated at the CAM-B3LYP/TZVP//B3LYP/6-31G(d) level, for the two diastereomers $\Lambda-Z n-2 R$ (left, average of 11 conformers) and $\Delta-Z n-2 R$ (right, average of 13 
conformers); all conformers are shown in Figures S6 and S7. Gaussian band shape with exponential bandwidth $\sigma=0.2 \mathrm{eV}$. Vertical bars represent calculated rotational strengths for the lowest-energy conformer of $\Lambda-\mathrm{Zn}-2 R$.

A full assignment of UV-Vis and ECD spectra in terms of well-defined single electronic excitations is made difficult by the relatively complex electronic system. In fact, every observed band is the superposition of different transitions, each of which is in turn due to the combination of several single excitation. Still, orbital and transition analysis clearly reveal the dominant role played by aromatic $\pi-\pi^{*}$ transitions. In particular, the long-wavelength ECD couplet observed between $340-430 \mathrm{~nm}$ is easily assigned to the exciton coupling ${ }^{34}$ between the first $\pi-\pi^{*}$ transition of the two naphthaldiminato chromophores, which occurs near $400 \mathrm{~nm}$ and, according to our TDDFT calculations on a truncated model for the ligand, is directed along the short axis of each chromophore (Figure 7). The frontier orbitals of the $C_{2}$-symmetric complex are the in-phase and out-of-phase combinations of the HOMO and LUMO orbitals on each chromophore; as a consequence, the HOMO and HOMO-1 orbitals of the complex, as well as the LUMO and LUMO +1 orbitals, are almost degenerate (Figure 8). The four possible single excitations combine in pairs giving rise to two transitions with opposite ECD sign, corresponding to the inphase and out-of-phase combinations of the two transitions on each chromophore, in accord with exciton theory. ${ }^{34}$

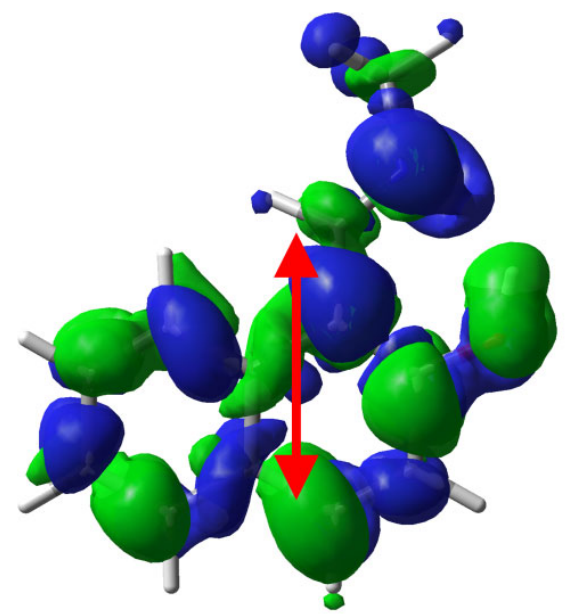

Figure 7. Transition density plot for the first transition $\left(\pi-\pi^{*}\right.$ type $)$ calculated at CAMB3LYP/TZVP level for a truncated model of ligands 1 and 2 (1-phenylethyl group replaced by methyl), and direction of the corresponding electric transition dipole moment (red arrow). 


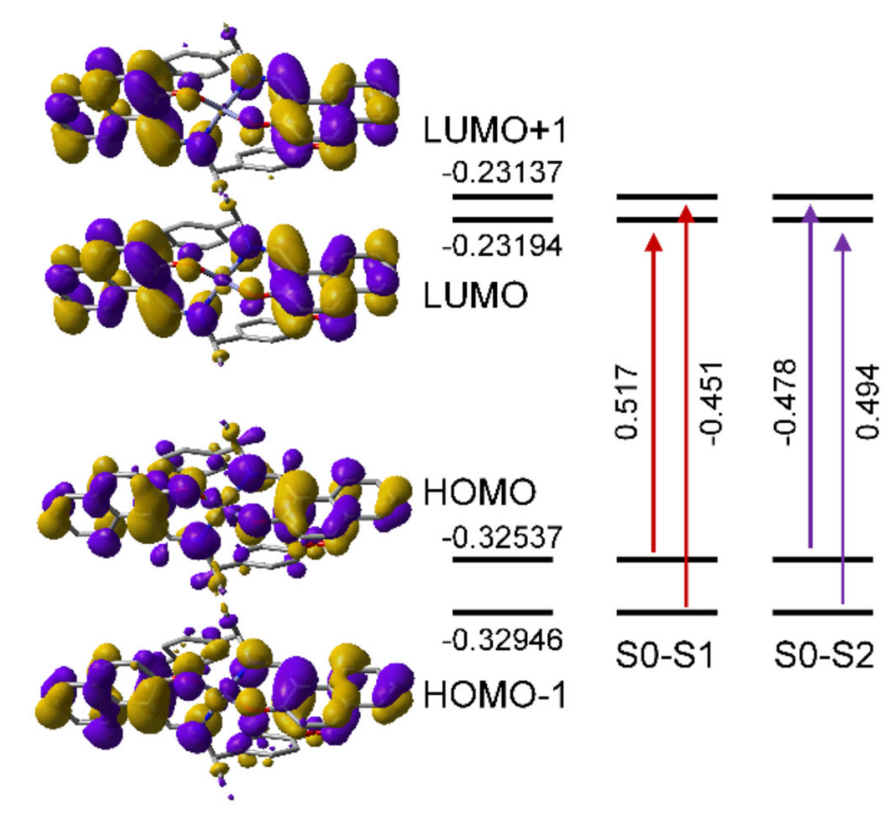

Figure 8. Frontier Kohn-Sham orbitals and assignment of the first two electronic transitions (S0S1 and S0-S2) calculated for compound $\Lambda-Z n-2 R$ at CAM-B3LYP/TZVP level. Horizontal numbers are orbital energies in hartrees; vertical numbers are CI coefficients.

The theory and application of the exciton chirality method to chromophoric complexes of transition metals have been established long time ago. ${ }^{46}$ However, it is very interesting to notice that a straightforward application of this method to the present complexes would lead to a wrong assignment of the absolute configuration. In fact, for all low-energy conformers of $\Lambda-Z n-2 R$ the transition dipole moments discussed above define a positive chirality (Figure 9), and a positive ECD couplet around $400 \mathrm{~nm}$ would be expected, ${ }^{34,46}$ in contrast with both the experimental and TDDFT-calculated ECD spectra. The reason for the apparent failure of the exciton chirality method must be sought in the approximation used to estimate the exciton coupling potential. ${ }^{47}$ In the classical application of the exciton chirality method, the coupling potential is implicitly - and most often even explicitly - approximated with the first term of a Columbic expansion of transition densities, namely the point dipole/point dipole term. In the current case, the potential estimated with the point-dipole approximation amounts to $\approx+20 \mathrm{~cm}^{-1}$ (lowest energy conformer of $\Lambda-\mathrm{Zn}-2 R$, point dipoles placed in the centre-of-mass of each chromophore, i.e. the middle of C1-C2 bonds, dipoles oriented as the red arrow in Figure 7). However, when the full TDDFT transition densities for the monomers are taken into account (shown in Figure 7, see Computational Section for details), ${ }^{48}$ the calculated potential is $\approx-100 \mathrm{~cm}^{-1}$, that is, its sign is changed from positive to negative. The potential estimated by TDDFT calculations of the entire 
compound is similarly $\approx-200 \mathrm{~cm}^{-1}$. Since the sign of the coupling potential affects the energy order of the two excitonic bands with opposite ECD sign, ${ }^{34}$ this sign reversal is responsible for the sign inversion of the couplet. Therefore compounds $\mathrm{Zn}-1$ and $\mathrm{Zn}-2$ clearly demonstrate the risk connected to the "visual" application of the exciton chirality method when new systems are considered, without verifying the sign of the coupling potential, as recently pointed out by Polavarapu and coworkers. ${ }^{49}$

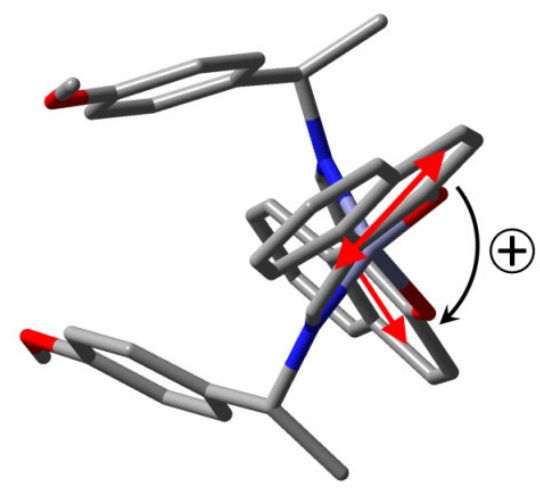

Figure 9. Exciton chirality defined by the transition dipoles polarized along the short axes of naphthaldiminato chromophores (see Figure 7) for the lowest energy DFT structure of compound $\Lambda-\mathrm{Zn}-2 R$. All other low energy minima have a similar orientation with positive chirality.

\section{${ }^{1}$ H NMR spectra.}

${ }^{1} \mathrm{H}$ NMR spectra show the peaks corresponding to the deprotonated Schiff base ligand coordinated to the $\mathrm{Zn}$ (II) ion (Figure 10 and Table 4). The peaks are shifted up-field in comparison to those of the free ligand and indicate the formation of the complexes. Each hydrogen gives rise to two peaks due to presence of both $\Lambda$ and $\Delta$-diastereomers in solution. ${ }^{12,18}$ The percentages of the two diastereomers $(\Delta v s . \Lambda)$, based on the respective peaks integration values, are $77 / 23$ for $\Delta / \Lambda-Z n-1 S$ and $83 / 17$ for $\Delta / \Lambda-Z n-2 S$ or $\Lambda / \Delta-Z n-2 R$ (Table 4). This proportion for the diastereomers is in reasonable agreement with the computational estimate (discussed above). In accordance with the solid state structures determinations, we assume that, for each hydrogen, the relatively up-field peak with higher integration value corresponds to the major diastereomer such as $\Delta-\mathrm{Zn}-1 S$ or $\Delta-\mathrm{Zn}-2 S$ or $\Lambda-\mathrm{Zn}-2 R$, while the downfield one to the minor diastereomer such as $\Lambda-\mathrm{Zn}-1 S$ or $\Lambda-\mathrm{Zn}-2 S$ or $\Delta-\mathrm{Zn}-2 R$. Thus, the methyl protons show two doublets at $\delta c a .1 .54 / 1.64 \mathrm{ppm}(J=6.6 \mathrm{~Hz})$, and methine proton shows two quartets at $c a$. $\delta$ $4.34 / 4.72 \mathrm{ppm}(J=6.8 \mathrm{~Hz})$. Similarly, the imine and methoxy protons show two singlets in each at $\delta$ ca.8.94/9.16 and 3.47/3.63 ppm, respectively. The phenolic proton, which shows a broad 
signal at $\delta c a .14 .70-14.85 \mathrm{ppm}$ in the free ligand due to strong intermolecular hydrogen bonding, ${ }^{15,17,28}$ is obviously absent in the complex.

If the dynamic equilibrium between two diastereomers $(\Delta v s . \Lambda)$ is sufficiently slow, it can easily be followed in solution using time dependent ${ }^{1} \mathrm{H}$ NMR technique. ${ }^{18} \mathrm{We}$ measured ${ }^{1} \mathrm{H}$ NMR spectra at different time intervals (ca. 10 min., $4 \mathrm{~h}$ and $20 \mathrm{~h}$ from complex dissolution in $\mathrm{CDCl}_{3}$ ) (Figure S8). Unlike our previous communication, ${ }^{18}$ where a diastereomeric equilibrium shifts from a single diastereomer (within 10 min of complex dissolution) to a diastereomeric mixture of 33/67 (40 $\mathrm{min}$ ) and 46/54 (36 h), the present results show no change of equilibrium in course of time of complex dissolution (Table 5). Rather, the complex undergoes a slow decomposition up to $c a$. $2.5 \%$ (within $20 \mathrm{~min}$.), $10 \%(4 \mathrm{~h})$ and $20 \%(20 \mathrm{~h})$ of the initial complex, as evidenced by the presence and growth of free ligand peaks (Figure S8 and Table 5). The presence of the phenolic peak $(\mathrm{O}-\mathrm{H})$ indicates the addition of protons, probably from water present in the sample, to the deprotonated Schiff base ligands. Also, absorption spectra measured at different time intervals (not shown) demonstrate slow decomposition of $\Delta / \Lambda-\mathrm{Zn}$ $1 S$, a common feature of labile tetrahedral $\mathrm{Zn}(\mathrm{II})-N, O$-chelate complexes. ${ }^{12,18,21}$
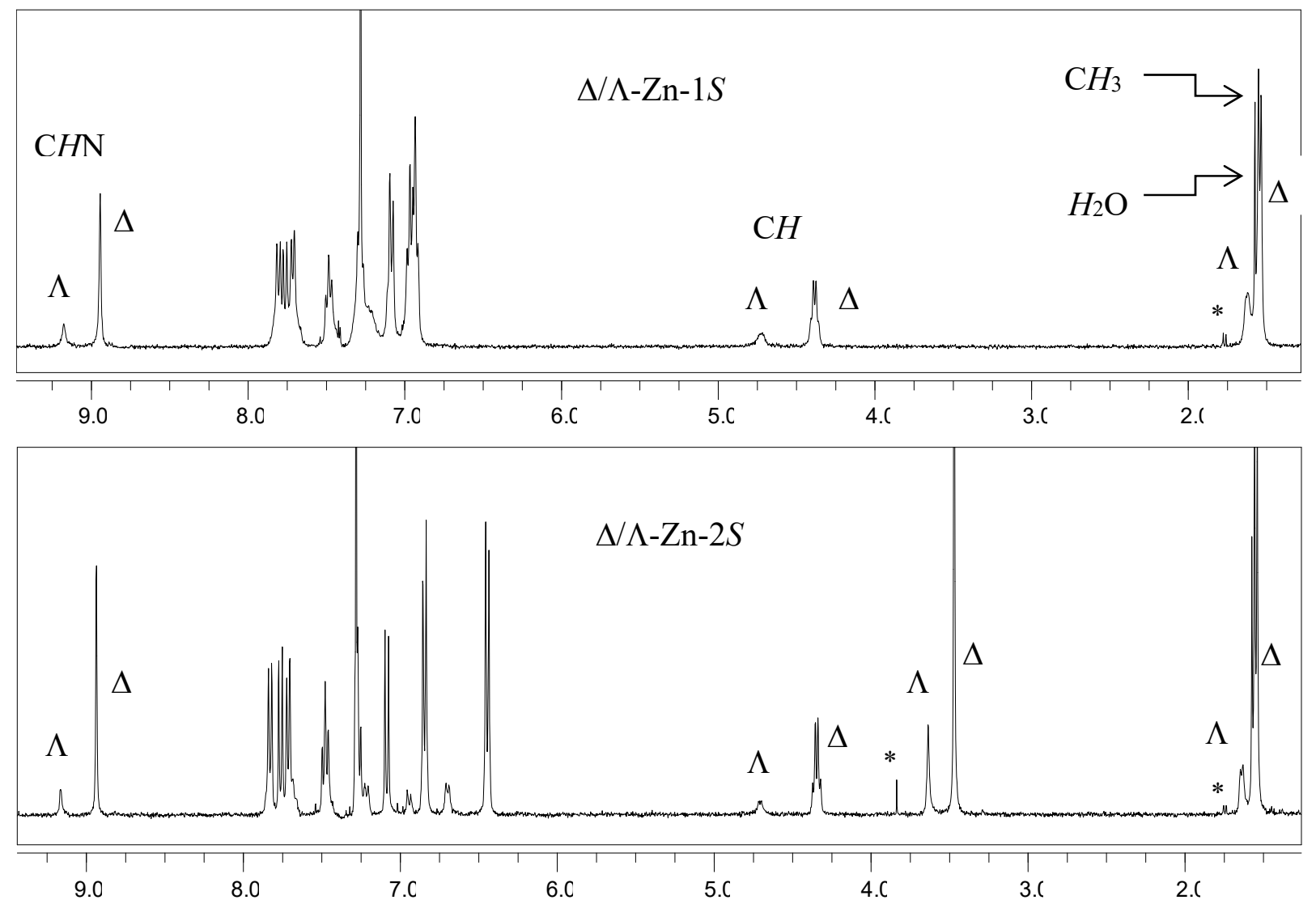


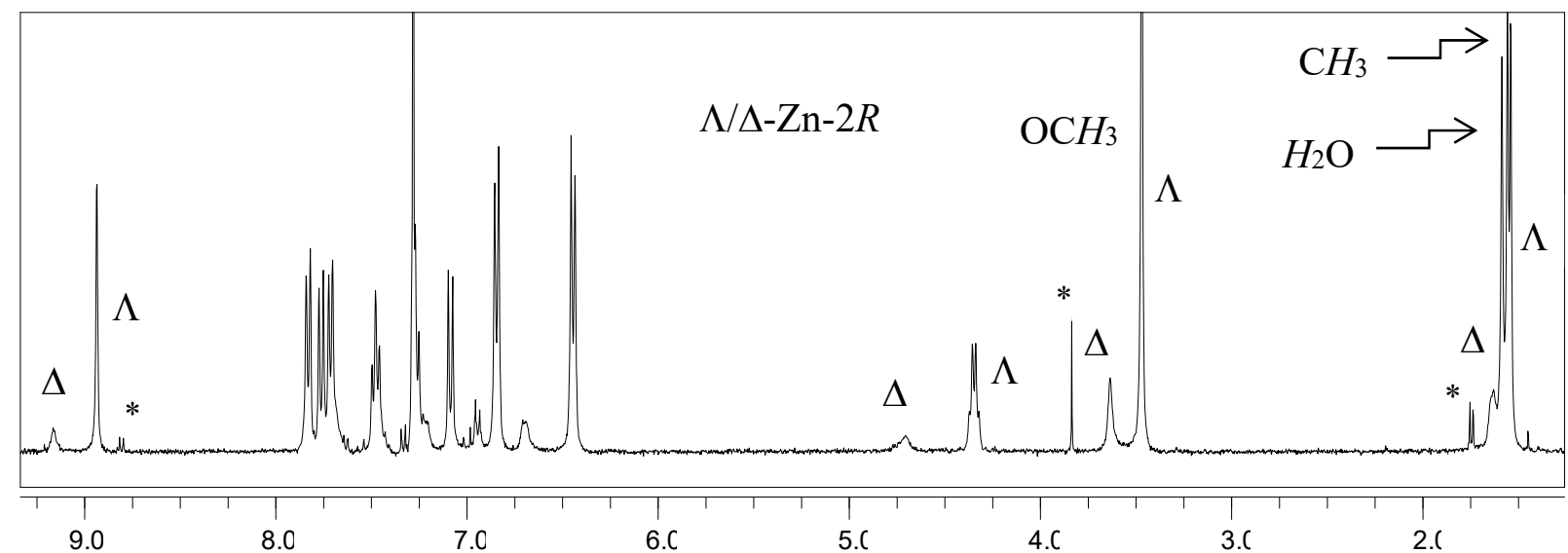

Figure 10. ${ }^{1} \mathrm{H}$ NMR (400 MHz) spectra of $\Delta / \Lambda-\mathrm{Zn}-1 S, \Delta / \Lambda-\mathrm{Zn}-2 S$ and $\Lambda / \Delta-\mathrm{Zn}-2 R$ in $\mathrm{CDCl}_{3}$ at $20{ }^{\circ} \mathrm{C}$ (asterisked peaks correspond to the free ligand in the sample).

Table 4. ${ }^{1} \mathrm{H}$ NMR (400 MHz) spectral data of $\Delta / \Lambda-\mathrm{Zn}-1 S, \Delta / \Lambda-\mathrm{Zn}-2 S$ and $\Lambda / \Delta-\mathrm{Zn}-2 R$ in $\mathrm{CDCl}_{3}$ at $20^{\circ} \mathrm{C}$.

\begin{tabular}{|l|c|l|l|l|l|}
\hline Entity & $\mathrm{CH}_{3}{ }^{\#}$ & $\mathrm{OCH}_{3}{ }^{\#}$ & $\mathrm{C}^{\#}$ & $\mathrm{Ar}-H$ & $\mathrm{C} H \mathrm{~N}^{\#}$ \\
\hline$\Delta / \Lambda-\mathrm{Zn}-1 S$ & $1.54 / 1.62$ & - & $4.38 / 4.72($ & $6.93(\mathrm{t}, J=6.5 \mathrm{~Hz}, 4 \mathrm{H}), 6.97(\mathrm{t}, J=$ & $8.94 / 9.18$ \\
& $(80 / 20)(\mathrm{d}$, & & $75 / 25) \quad(\mathrm{q}$, & $6.8 \mathrm{~Hz}, 2 \mathrm{H}), 7.08(\mathrm{~d}, J=8.4 \mathrm{~Hz}, 4 \mathrm{H}), 7.28$ & $(78 / 22)$ \\
& $J=6.8 \mathrm{~Hz}$, & & $J=6.8 \mathrm{~Hz}$, & $(\mathrm{t}, J=6.4 \mathrm{~Hz}, 4 \mathrm{H}), 7.48(\mathrm{t}, J=7.4 \mathrm{~Hz}$, & $(\mathrm{s} .1 \mathrm{H})$ \\
& $6 \mathrm{H})$ & & $2 \mathrm{H})$ & $2 \mathrm{H}), 7.71(\mathrm{~d}, J=8.0 \mathrm{~Hz}, 2 \mathrm{H}), 7.76(\mathrm{~d}, J=$ & \\
& & & & $9.2 \mathrm{~Hz}, 2 \mathrm{H}), 7.80(\mathrm{~d}, J=8.4 \mathrm{~Hz}, 2 \mathrm{H})$ & \\
\hline$\Lambda / \Delta-\mathrm{Zn}-2 R$ & $1.55 / 1.63$ & $3.47 / 3.63$ & $4.34 / 4.71$ & $6.44(\mathrm{~d}, J=8.0 \mathrm{~Hz}, 4 \mathrm{H}), 6.84(\mathrm{~d}, J=$ & $8.94 / 9.16$ \\
& $(83 / 17)(\mathrm{d}$, & $(81 / 19)$ & $(80 / 20)(\mathrm{q}$, & $8.4 \mathrm{~Hz}, 4 \mathrm{H}), 7.08(\mathrm{~d}, J=9.2 \mathrm{~Hz}, 2 \mathrm{H}), 7.27$ & $(83 / 17)$ \\
& $J=6.5 \mathrm{~Hz}$, & $(\mathrm{s}, 6 \mathrm{H})$ & $J=6.8 \mathrm{~Hz}$, & $(\mathrm{t}, J=6.4 \mathrm{~Hz}, 2 \mathrm{H}), 7.48(\mathrm{t}, J=7.7 \mathrm{~Hz}$, & $(\mathrm{s} .1 \mathrm{H})$ \\
& $6 \mathrm{H})$ & & $2 \mathrm{H})$ & $2 \mathrm{H}), 7.71(\mathrm{~d}, J=8.0 \mathrm{~Hz}, 2 \mathrm{H}), 7.76(\mathrm{~d}, J=$ & \\
& & & & $9.2 \mathrm{~Hz}, 4 \mathrm{H}), 7.83(\mathrm{~d}, J=8.4 \mathrm{~Hz}, 2 \mathrm{H})$ & \\
\hline \multirow{5}{*}{$\Delta / \Lambda-\mathrm{Zn}-2 S$} & $1.54 / 1.64$ & $3.47 / 3.64$ & $4.35 / 4.70($ & $6.44(\mathrm{~d}, J=8.0 \mathrm{~Hz}, 4 \mathrm{H}), 6.84(\mathrm{~d}, J=$ & $8.94 / 9.16$ \\
& $(84 / 16)(\mathrm{d}$, & $(82 / 18)$ & $81 / 19) \quad(\mathrm{q}$, & $8.4 \mathrm{~Hz}, 4 \mathrm{H}), 7.08(\mathrm{~d}, J=9.2 \mathrm{~Hz}, 2 \mathrm{H}), 7.27$ & $(84 / 16)$ \\
& $J=6.5 \mathrm{~Hz}$, & $(\mathrm{s}, 6 \mathrm{H})$ & $J=6.8 \mathrm{~Hz}$, & $(\mathrm{t}, J=7.4 \mathrm{~Hz}, 2 \mathrm{H}), 7.48(\mathrm{t}, J=7.4 \mathrm{~Hz}$, & $(\mathrm{s} .1 \mathrm{H})$ \\
& $6 \mathrm{H})$ & & $2 \mathrm{H})$ & $6 \mathrm{H}), 7.71(\mathrm{~d}, J=7.6 \mathrm{~Hz}, 2 \mathrm{H}), 7.76(\mathrm{~d}, J=$ & \\
& & & & $9.2 \mathrm{~Hz}, 2 \mathrm{H}), 7.83(\mathrm{~d}, J=8.4 \mathrm{~Hz}, 2 \mathrm{H})$ & \\
\hline
\end{tabular}

${ }^{\#}$ Diastereomeric peaks ratios are in parentheses.

\section{Variable-temperature ${ }^{1} \mathrm{H}-\mathrm{NMR}$ and ECD spectra.}

To further investigate the diastereomeric equilibrium and study its dynamics, we measured ${ }^{1} \mathrm{H}$ NMR spectra of $\Delta / \Lambda-\mathrm{Zn}-1 S$ at variable temperatures starting from 20 to $-50{ }^{\circ} \mathrm{C}$ and then again to $35^{\circ} \mathrm{C}$ (Figure 11). The spectra were measured within $1.5 \mathrm{~h}$ of complex dissolution in $\mathrm{CDCl}_{3}$, so that no decomposition occurs. This is further confirmed by reproduce of data at 20 
${ }^{\circ} \mathrm{C}$. The experimental results clearly show the occurrence of a diastereomeric equilibrium (Figure 11-12). The fraction of the major $\Delta-\mathrm{Zn}-1 S$ diastereomer changes from $77 \%$ at $20{ }^{\circ} \mathrm{C}$ to $87 \%$ at $-50{ }^{\circ} \mathrm{C}$ and $73 \%$ at $35{ }^{\circ} \mathrm{C}$ (Figure 12 and Table 5). Obviously, a lower temperature shifts the equilibrium towards the major diastereomer $\Delta-\mathrm{Zn}-1 S$, while a higher temperature increases the relative amount of the minor diastereomer $\Lambda-\mathrm{Zn}-1 S$. The plot of the diastereomeric ratio is also approximately linear with temperature (Figure 12). Interestingly, a classical Van't Hoff analysis and linear fit of the data (not shown) demonstrates that the equilibrium is entropy-driven at room temperature.

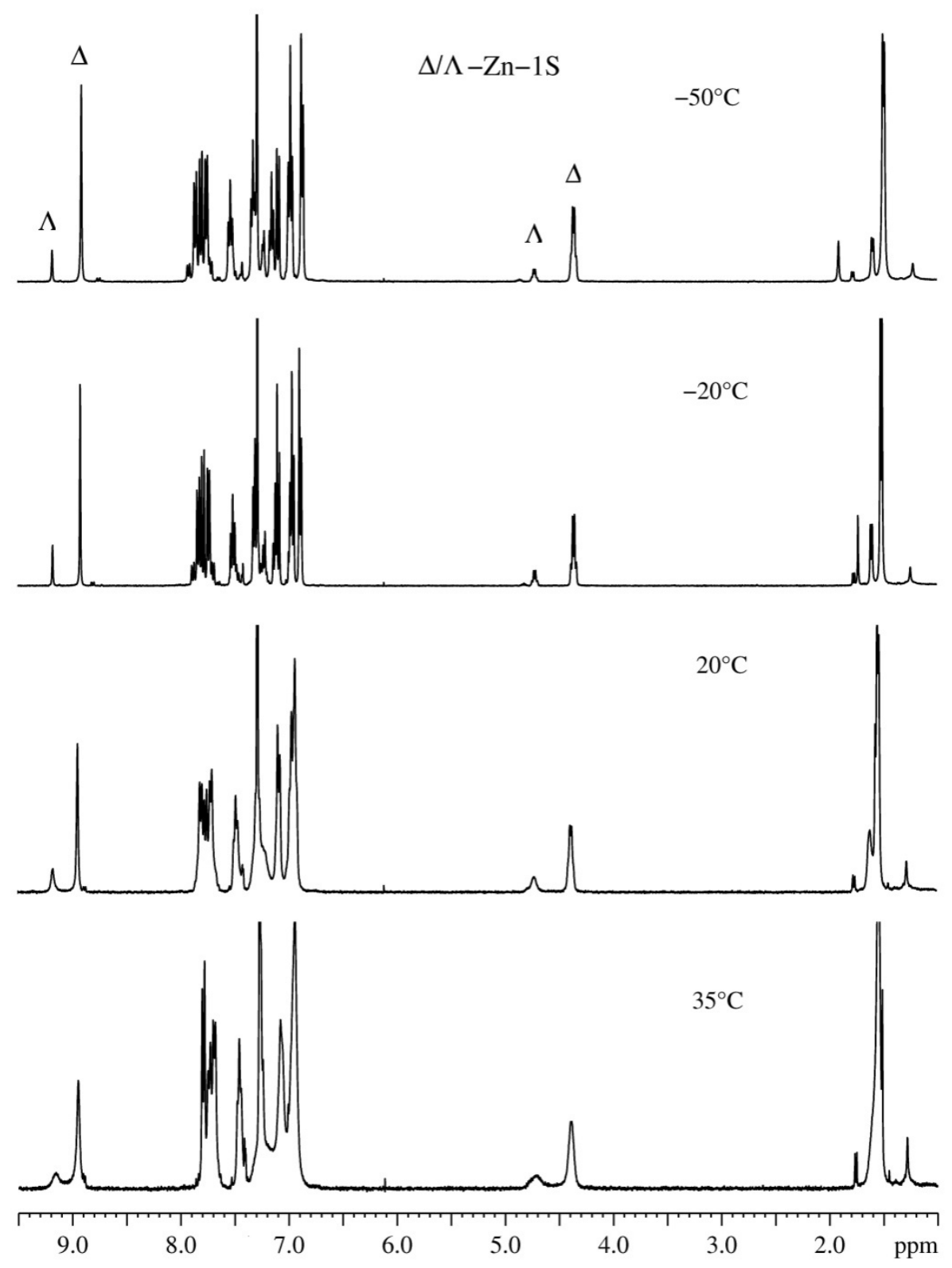


Figure 11. ${ }^{1} \mathrm{H}$ NMR (400 MHz) spectra of compound $\Delta / \Lambda-Z n-1 S$ in $\mathrm{CDCl}_{3}$ at variable temperature.

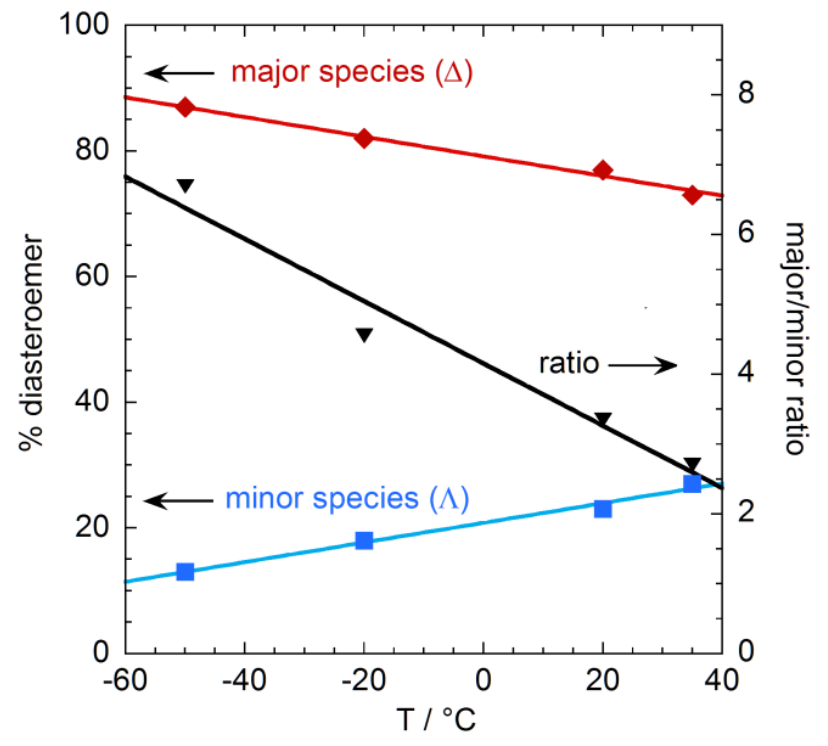

Figure 12. Changes of diastereomer $\Delta$ vs. $\Lambda$ proportion $(\%)$ and ratio $(\Delta / \Lambda)$ with temperature for $\Delta / \Lambda-\mathrm{Zn}-1 S$ in $\mathrm{CDCl}_{3}$, from $\mathrm{VT}-{ }^{1} \mathrm{H}-\mathrm{NMR}$ spectra.

Table 5. Change of diastereomers in $\Lambda$ or $\Delta-\mathrm{Zn}-R(\Delta$ or $\Lambda-\mathrm{Zn}-S)$ at variable time and temperatures in $\mathrm{CDCl}_{3}$, respectively.

\begin{tabular}{|l|l|l|l|l|l|}
\hline Entry & Temp. $/{ }^{\circ} \mathrm{C}$ & Time $^{1}$ & $\begin{array}{l}\text { Free ligand } \\
(\%)^{2}\end{array}$ & $\begin{array}{l}\text { Major diastereomer } \\
(\%)^{3}\end{array}$ & $\begin{array}{l}\text { Minor diastereomer } \\
(\%)^{3}\end{array}$ \\
\hline \multirow{4}{*}{$\Delta / \Lambda$-Zn-1S } & 20 & $10 \mathrm{~min}$ & 1.3 & $77.6(\Delta$-isomer $)$ & $22.4(\Lambda$-isomer $)$ \\
& & $4 \mathrm{~h}$ & 10 & 76.0 & 24.0 \\
& $20 \mathrm{~h}$ & 22 & 76.9 & 23.1 \\
\cline { 2 - 6 } & -50 & $10 \mathrm{~min}$ & 2.5 & $76.8(\Delta$-isomer $)$ & $23.2(\Lambda$-isomer $)$ \\
& -20 & $1 \mathrm{~h}$ & 2.5 & 86.7 & 13.3 \\
& 20 & $1 \mathrm{~h} 15 \mathrm{~min}$ & 2.5 & 77.0 & 18.4 \\
& 35 & $1 \mathrm{~h} 30 \mathrm{~min}$ & 2.5 & 73.0 & 23.0 \\
& 20 & $20 \mathrm{~min}$ & 2.5 & $83.3(\Lambda$-isomer $)$ & $16.7(\Delta$-isomer $)$ \\
\hline$\Lambda / \Delta$-Zn-2R & 20 & $4 \mathrm{~h}$ & 9 & 83.8 & 16.2 \\
& & $20 \mathrm{~h}$ & 20 & 85.1 & 14.9 \\
\hline$\Delta / \Lambda$-Zn-2S & 20 & $15 \mathrm{~min}$ & 1.4 & $83.6(\Delta$-isomer $)$ & $16.4(\Lambda$-isomer $)$ \\
\hline
\end{tabular}

${ }^{1}$ Corresponds to the time of spectral run after dissolution of the complex in $\mathrm{CDCl}_{3}$.

${ }^{2}$ Free ligand (\%) resulting from decomposition of complex in course of time in $\mathrm{CDCl}_{3}$. 
${ }^{3}$ calculated from integration values of corresponding peaks for the imine or methyl or methine protons.

A consistent picture about the diastereomeric equilibrium is also provided by variable temperature ECD spectra, which were recorded in methylcyclohexane between $-40^{\circ}$ and $80^{\circ} \mathrm{C}$ on compound $\mathrm{Zn}-1 R$ in the exciton couplet region (Figure 13). The experimental and theoretical ECD analysis discussed above has established that the two diastereomers $\Lambda$-Zn- $1 R$ (major species) and $\Delta-\mathrm{Zn}-1 R$ (minor species) would have almost mirror-image ECD spectra. It is thus expected that, upon cooling, the ECD should increase in intensity, and upon heating, they should decrease in intensity, while maintaining the overall shape well preserved. This is fact clearly observed in VT-ECD spectra (Figure 13). The variation of the couplet amplitude is approximately linear with the temperature (see inset in Figure 13), pointing again to a single equilibrium phenomenon. The estimated temperature necessary to reach a $1: 1$ diastereomeric mixture, corresponding to a vanishing ECD exciton couplet, is $113^{\circ} \mathrm{C}$.

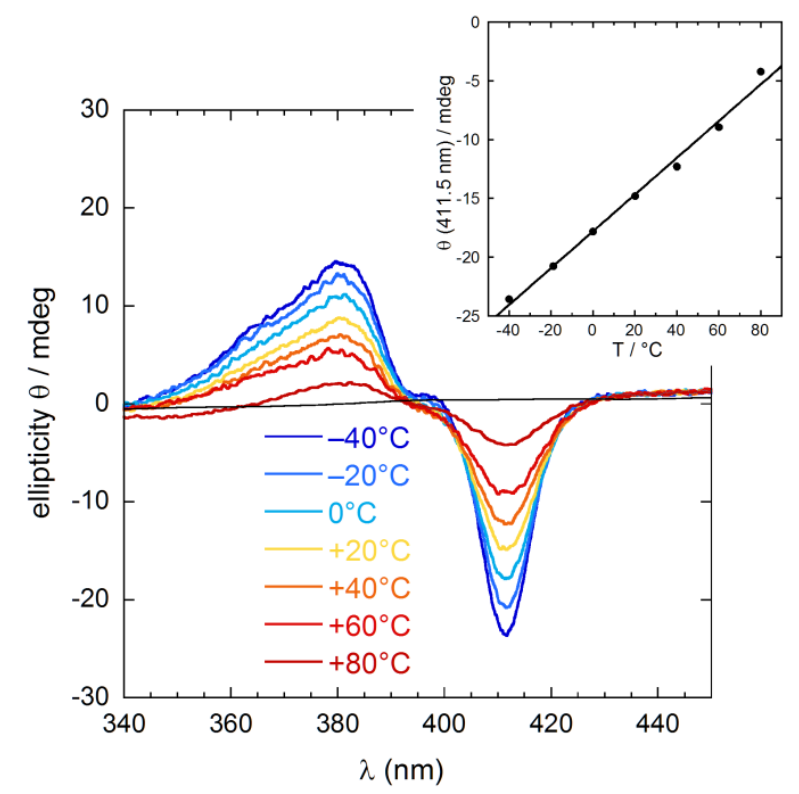

Figure 13. Variable-temperature ECD spectra for $\mathrm{Zn}-1 R 0.86 \mathrm{mM}$ in methylcyclohexane; cell path length $0.2 \mathrm{~mm}$. The black line is the solvent blank spectrum (not subtracted). Inset: plot of ellipticity at $411.5 \mathrm{~nm}$ (couplet negative maximum) as a function of temperature.

\section{CONCLUSIONS}

Synthesized $\quad \Lambda / \Delta \quad$ or $\quad \Delta / \Lambda$-bis $[\{(R \quad$ or $\quad S)$-N-(Ar)ethyl-2-oxo-1-naphthaldiminato$\left.\kappa^{2} \mathrm{~N}, \mathrm{O}\right\}$ ]zinc(II) complexes adopt nearly tetrahedral geometry with induced $\Lambda$ vs. $\Delta$ configuration at zinc(II) as evidenced by X-ray analyses. The $R$ or $S$-ligand configuration induces diastereoselectively the $\Lambda$ - or $\Delta$-metal configuration, respectively, in the solid state. In 
solution, a diastereomeric equilibrium between $\Lambda$ and $\Delta$ forms exists for both complexes, as evidenced by ${ }^{1} \mathrm{H}$ NMR spectroscopy. The nature of the major species is definitely established by means of ECD spectra in combination with TDDFT calculations. ECD spectra show an exciton couplet in the long wavelength region whose sign is at odds with the prediction based on the exciton chirality rule. This contradiction was rationalized by observing that the exciton coupling potential changes in sign when passing from the common point-dipole approximation to a more correct evaluation using theoretical transition densities. Variable temperature ${ }^{1} \mathrm{H}$ NMR and ECD spectra demonstrate the occurrence of a diastereomeric equilibrium in solution, which is shifted toward the most stable $\Delta-\mathrm{Zn}$ configuration (for $S$-ligand) at low temperature. DSC analyses show quantitative diastereomeric excess at solid state for compound $\mathrm{Zn}-2 \mathrm{R} / \mathrm{S}$ which is comparable to the ratio found in solution at room temperature.

\section{MATERIALS AND METHODS}

IR-spectra were recorded on a Nicolet iS10 spectrometer as $\mathrm{KBr}$ dics at ambient temperature. UV-vis absorption spectra were obtained with Shimadzu UV 1800 spectrophotometer in cyclohexane at $25{ }^{\circ} \mathrm{C}$. Elemental analyses were done on a Vario EL instrument from Elementar Analysensysteme. It became apparent that the samples were hygroscopic and absorbed some water upon storage under ambient air. Such storage and handling (weighing) under ambient air was unavoidable during the submission and sample preparation for $\mathrm{CHN}$ analyses. Hence, the calculated CHN results of the "dry samples" differ from the found values but match if 0.2-0.3 equivalents of water were considered. The presence of water in the samples is also confirmed by the NMR spectra (see Fig. 10). Thermal analysis was performed on a SHIMADZU DSC-60 differential scanning calorimeter (DSC), heating range at $303-553 \mathrm{~K}$ and rate at $10 \mathrm{~K} \mathrm{~min}^{-1}$. ECD spectra were obtained with Olis RSM100 CD and Jasco J-715 spectropolarimeters in cyclohexane at $20^{\circ} \mathrm{C}$. Solid-state samples for CD were prepared $^{20}$ by mixing 1-2 small crystals with approximately $100 \mathrm{mg}$ of oven-dried $\mathrm{KCl}$, then pressing the disc at 10 tons for about $15 \mathrm{~min}$. The resulting disc was checked for homogeneity and transparency. Several discs were prepared for each compound. For each disc, four different spectra were recorded by rotating the disc around the incident light direction and by flipping the disc with respect to the vertical, to check the presence of artifacts. ${ }^{1} \mathrm{H}-\mathrm{NMR}$ spectra were run on a Bruker $\mathrm{AV} 400$ spectrometer using $\mathrm{CDCl}_{3}$ as solvent at $20{ }^{\circ} \mathrm{C}$. ESI (positive) mass spectra were taken on a Thermo-Finnigan TSQ 700. Isotopic distributions for ${ }^{64 / 66} \mathrm{Zn}$ containing ions are clearly visible in the mass spectra. The syntheses of enantiopure Schiff bases, $(R$ or $S)$ N-1-(Ar)ethyl-2-oxo-1-naphthaldimine were described in our previous literature. ${ }^{27}$ 


\section{General procedure to synthesize the complexes.}

Two equivalents of enantiopure ( $R$ or $S)$-N-1-(phenyl)ethyl-2-oxo-1-naphthaldimine (1R or 1S) (551 mg, $2.0 \mathrm{mmol})$ dissolved in $10 \mathrm{~mL}$ of methanol was poured into $10 \mathrm{~mL}$ of a hot methanolic solution of $\mathrm{Zn}\left(\mathrm{O}_{2} \mathrm{CCH}_{3}\right)_{2} \cdot 2 \mathrm{H}_{2} \mathrm{O}(219 \mathrm{mg}, 1.0 \mathrm{mmol})$. Added $\mathrm{NaHCO}_{3}$ (168 mg, 2.0 mmol) dissolved in $5 \mathrm{~mL}$ methanol into this solution and continued reflux for $c a .12 \mathrm{~h}$. Color changes from light yellow to bright yellow. Filtered the solution and then reduced the volume by solvent evaporation in vacuo to ca.50\%.Left standing this concentrated solution for crystallization via slow solvent evaporation at room temperature. Light yellow crystals of $\mathrm{Zn}-1 \mathrm{~S}$ or $\mathrm{Zn}-1 R$ were obtained within 6-7 d. The crystals were separated, washed three times with few drops of methanol and dried in a desiccator over $\mathrm{CaCl}_{2}$ for several days. The same procedure was followed for syntheses of $\mathrm{Zn}-2 S$ or $\mathrm{Zn}-2 R$, using ( $R$ or $S)-\mathrm{N}-1-\left(p-\mathrm{MeOC}_{6} \mathrm{H}_{4}\right)$ ethyl-2-oxo-1naphthaldimine $(2 R$ or $2 S)$.

$\operatorname{Bis}\left\{(R)-N-(p h e n y l) e t h y l-2-o x 0-1-n a p h t h a l d i m i n a t o-\kappa^{2} N, O\right\} \operatorname{zinc}(I I) \quad(Z n-1 R):$ Yield 450 mg $(73 \%)$. - IR $\left(\mathrm{KBr}, \mathrm{cm}^{-1}\right): v=3055,3033,2967,2928 \mathrm{w}(\mathrm{C}-\mathrm{H}), 1616,1603,1586 \mathrm{vs}(\mathrm{C}=\mathrm{N})$, and $1538 \mathrm{~s}(\mathrm{C}=\mathrm{C}) .-\mathrm{MS}(\mathrm{ESI}+): m / z(\%)=613(5)[M+\mathrm{H}]^{+}, 605(5)\left[(\mathrm{HL} 1)_{2}+\mathrm{CH}_{3} \mathrm{OH}+\mathrm{Na}\right]^{+}$, $551 / 573(45 / 30)\left[(\mathrm{HL} 1)_{2}+\mathrm{H} / \mathrm{Na}\right]^{+}, 308 / 330(15 / 30)\left[\mathrm{HL} 1+\mathrm{CH}_{3} \mathrm{OH}+\mathrm{H} / \mathrm{Na}\right]^{+}$and 276/298 (100/5) $[\mathrm{HL} 1+\mathrm{H} / \mathrm{Na}]^{+} .-\mathrm{C}_{3} \mathrm{H}_{32} \mathrm{~N}_{2} \mathrm{O}_{2} \mathrm{Zn} \cdot 0.3 \mathrm{H}_{2} \mathrm{O}$ (619.47): calcd. C 73.68, H 5.30, N 4.52; found $\mathrm{C}$ 73.31, H 4.87, N 4.31\%.

Bis $\left\{(S)-N-\left(\right.\right.$ phenyl)ethyl-2-oxo-1-naphthaldiminato- $\left.\kappa^{2} N, O\right\}$ zinc(II) (Zn-1S): Yield 430 $\operatorname{mg}(70 \%) .-$ IR $\left(\mathrm{KBr}, \mathrm{cm}^{-1}\right): v=3054,3030,2965,2925 \mathrm{w}(\mathrm{C}-\mathrm{H}), 1617,1601,1586 \mathrm{vs}(\mathrm{C}=\mathrm{N})$, and $1537 \mathrm{~s}(\mathrm{C}=\mathrm{C}) .-\mathrm{MS}(\mathrm{ESI}+): m / z(\%)=613(10)[M+\mathrm{H}]^{+}, 605(50)\left[(\mathrm{HL} 1)_{2}+\mathrm{CH}_{3} \mathrm{OH}+\mathrm{Na}\right]^{+}$, and $276(100)[\mathrm{HL} 1+\mathrm{H} / \mathrm{Na}]^{+} .-\mathrm{C}_{38} \mathrm{H}_{32} \mathrm{~N}_{2} \mathrm{O}_{2} \mathrm{Zn} \cdot 0.3 \mathrm{H}_{2} \mathrm{O}$ (619.47): calcd. C 73.68, H 5.30, N 4.52; found C 72.91, H 4.92, N 4.42\%.

$\operatorname{Bis}\left\{(R)-\mathrm{N}-\left(p\right.\right.$-methoxphenyl)ethyl-2-oxo-1-naphthaldiminato- $\left.\kappa^{2} N, O\right\} \operatorname{zinc}(\mathrm{II}) \quad(\mathrm{Zn}-2 R)$ : Yield $470 \mathrm{mg}(70 \%)$. - IR $\left(\mathrm{KBr}, \mathrm{cm}^{-1}\right): \mathrm{v}=3050,3032,2966,2931 \mathrm{w}(\mathrm{C}-\mathrm{H}), 1616,1603$, $1587 \mathrm{vs}(\mathrm{C}=\mathrm{N})$, and $1540 \mathrm{~s}(\mathrm{C}=\mathrm{C})$. $-\mathrm{MS}(\mathrm{ESI}+): m / z(\%)=673(5)[M+\mathrm{H}]^{+}$. $\mathrm{C}_{40} \mathrm{H}_{36} \mathrm{~N}_{2} \mathrm{O}_{4} \mathrm{Zn} \cdot 0.2 \mathrm{H}_{2} \mathrm{O}$ (677.72): calcd. C 70.89, H 5.41, N 4.13; found $\mathrm{C} 70.91, \mathrm{H}$ 5.20, N $4.04 \%$.

$\operatorname{Bis}\left\{(S)-\mathrm{N}-\left(p\right.\right.$-methoxphenyl)ethyl-2-oxo-1-naphthaldiminato- $\left.\kappa^{2} N, O\right\} \operatorname{zinc}(\mathrm{II}) \quad(\mathrm{Zn}-2 S)$ : Yield $500 \mathrm{mg}(74 \%)$. - IR $\left(\mathrm{KBr}, \mathrm{cm}^{-1}\right): v=3058,3030,2968,2931 \mathrm{w}(\mathrm{C}-\mathrm{H}), 1617,1603$, 1586vs $(\mathrm{C}=\mathrm{N})$, and 1540s $(\mathrm{C}=\mathrm{C}) .-\mathrm{MS}(\mathrm{ESI}+): m / z(\%)=673(5)[M+\mathrm{H}]^{+}, 611 / 633(50 / 70)$ $\left[(\mathrm{HL} 1)_{2}+\mathrm{H} / \mathrm{Na}\right]^{+}, 392(10)\left[\mathrm{HL} 1+2 \mathrm{CH}_{3} \mathrm{OH}+\mathrm{Na}\right]^{+}, 360(60)\left[\mathrm{HL} 1+\mathrm{CH}_{3} \mathrm{OH}+\mathrm{Na}\right]^{+}$, and 306/328 
(100/10) $[\mathrm{HL} 1+\mathrm{H} / \mathrm{Na}]^{+} .-\mathrm{C}_{40} \mathrm{H}_{36} \mathrm{~N}_{2} \mathrm{O} 4 \mathrm{Zn} \cdot 0.2 \mathrm{H}_{2} \mathrm{O}$ (677.72): calcd. C 70.89, H 5.41, N 4.13; found C 70.78, H 5.23, N 4.00\%.

X-ray crystallography. Single crystals of Zn- $1 S, \mathrm{Zn}-1 R, \mathrm{Zn}-2 S$, and $\mathrm{Zn}-2 R$ were carefully selected under a polarizing microscope and mounted on a loop. Data collection: ${ }^{24}$ Bruker APEX II CCD diffractometer, multi-layer mirror monochromator, Mo-K $\alpha$ radiation $(\lambda=$ $0.71073 \AA$ ); $\omega$-scans (see Table 6). Data collection and cell refinement with APEX $2,{ }^{50}$ data reduction with SAINT (Bruker). ${ }^{51}$ Structure analysis and refinement: ${ }^{24}$ The structures were solved by direct methods (SHELXS-97), ${ }^{52}$ refinement was done by full-matrix least squares on $F^{2}$ using the SHELXL-97 program suite, ${ }^{51}$ empirical (multi-scan) absorption correction with SADABS (Bruker). ${ }^{53}$ All non-hydrogen positions were refined with anisotropic temperature factors. Hydrogen atoms for aromatic $\mathrm{CH}$, aliphatic or olefinic $\mathrm{CH}, \mathrm{CH}_{2}$ groups were positioned geometrically $(\mathrm{C}-\mathrm{H}=0.95 \AA$ for aromatic $\mathrm{CH}, \mathrm{C}-\mathrm{H}=0.95 \AA$ for olefinic $\mathrm{CH}, 1.00$ for aliphatic $\mathrm{CH}$ and $0.98 \AA$ for $\mathrm{CH}_{3}$,) and refined using a riding model (AFIX 43 for aromatic $\mathrm{CH}$, AFIX 13 for aliphatic $\mathrm{CH}$, AFIX 137 for $\left.\mathrm{CH}_{3}\right)$, with $\mathrm{U}_{\text {iso }}(\mathrm{H})=1.2 \mathrm{U}_{\mathrm{eq}}\left(\mathrm{CH}, \mathrm{CH}_{2}\right)$ and $\mathrm{U}_{\text {iso }}(\mathrm{H})=$ $1.5 \mathrm{U}_{\mathrm{eq}}\left(\mathrm{CH}_{3}\right)$. Details of the X-ray structure determinations and refinements are provided in Table 6. Graphics were drawn with DIAMOND (Version 3.2) ${ }^{54}$ Computations on the supramolecular interactions were carried out with PLATON for Windows. ${ }^{55}$ The structural data for this paper have been deposited with the Cambridge Crystallographic Data Center (CCDC: 1453324-1453327). These data can be obtained free of charge via www.ccdc.cam.ac.uk/data_request/cif.

Table 6. Crystal data and structure refinement for the compounds.

\begin{tabular}{|c|c|c|c|c|}
\hline Compound & $\Lambda-\mathrm{Zn}-1 R$ & $\Delta-\mathrm{Zn}-1 S$ & $\Lambda-Z \mathrm{n}-2 R$ & $\Delta-\mathrm{Zn}-2 S$ \\
\hline Data set & ZnR12B1 & ZnR33A & ZnR13A & ZnR29 \\
\hline Empirical formula & $\mathrm{C}_{38} \mathrm{H}_{32} \mathrm{~N}_{2} \mathrm{O}_{2} \mathrm{Zn}_{1}$ & $\mathrm{C}_{38} \mathrm{H}_{32} \mathrm{~N}_{2} \mathrm{O}_{2} \mathrm{Zn}_{1}$ & $\mathrm{C}_{40} \mathrm{H}_{36} \mathrm{~N}_{2} \mathrm{O}_{4} \mathrm{Zn}_{1}$ & $\mathrm{C}_{40} \mathrm{H}_{36} \mathrm{~N}_{2} \mathrm{O}_{4} \mathrm{Zn}_{1}$ \\
\hline $\mathrm{M} / \mathrm{g} \mathrm{mol}^{-1}$ & 614.02 & 614.02 & 674.08 & 674.08 \\
\hline Crystal size $/ \mathrm{mm}^{3}$ & $0.06 \times 0.04 \times 0.02$ & $0.29 \times 0.11 \times 0.05$ & $0.35 \times 0.16 \times 0.06$ & $0.45 \times 0.18 \times 0.06$ \\
\hline Temperature/K & 100 & 173 & 100 & 100 \\
\hline$\theta$ range $/^{\circ}$ (completeness) & $2.401-23.494(99.7 \%)$ & $2.423-21.583(99.3 \%)$ & $2.56-27.995(99.5 \%)$ & $2.167-27.986(99.2 \%)$ \\
\hline h; k; l range & $\pm 11, \pm 11, \pm 23$ & $\pm 9 ; \pm 9 ; \pm 19$ & $\pm 16 ; \pm 26 ; \pm 21$ & $\pm 16 ; \pm 25 ; \pm 20$ \\
\hline Crystal system & Triclinic & Triclinic & Monoclinic & Monoclinic \\
\hline Space group & P 1 (no. 1) & P 1 (no. 1) & P 21 (no. 4) & P 21 (no. 4) \\
\hline $\mathrm{a} / \AA$ & $9.4341(16)$ & $9.391(4)$ & $12.0388(9)$ & $12.0424(8)$ \\
\hline $\mathrm{b} / \AA$ & $9.4537(16)$ & $9.421(4)$ & $19.0223(14)$ & $18.9648(13)$ \\
\hline$c / \AA$ & $18.850(3)$ & $18.770(9)$ & $15.3420(11)$ & $15.3577(10)$ \\
\hline$a /^{\circ}$ & $88.250(10)$ & $80.467(6)$ & 90 & 90 \\
\hline $\mathrm{B} /{ }^{\circ}$ & $80.070(10)$ & $88.410(7)$ & $108.780(2)$ & $108.771(2)$ \\
\hline$\gamma /{ }^{\circ}$ & 63.951(9) & $63-660(6)$ & 90 & 90 \\
\hline $\mathrm{V} / \AA^{3}$ & $1485.8(5)$ & $1465.7(12)$ & $3326.4(4)$ & $3320.9(4)$ \\
\hline Z & 2 & 2 & 4 & 4 \\
\hline $\mathrm{D}_{\text {calc } / \mathrm{g} \mathrm{cm}^{-3}}$ & 1.372 & 1.391 & 1.346 & 1.348 \\
\hline$\mu(\mathrm{Mo} \mathrm{Ka}) / \mathrm{mm}^{-1}$ & 0.864 & 0.876 & 0.783 & 0.784 \\
\hline $\mathrm{F}(000)$ & 640 & 640 & 1408 & 1408 \\
\hline
\end{tabular}




\begin{tabular}{|c|c|c|c|c|}
\hline Max./min. transmission & $0.7454 / 0.6696$ & $0.7447 / 0.6252$ & $0.9545 / 0.7712$ & $0.9544 / 0.7192$ \\
\hline Reflections collected & 24620 & 7906 & 43015 & 41002 \\
\hline Independent reflect. $\left(\mathrm{R}_{\text {int }}\right)$ & $11460(0.0540)$ & $6656(0.0387)$ & $18875(0.0438)$ & $17758(0.0463)$ \\
\hline Data/restraints/parameters & $11460 / 3 / 780$ & $6656 / 3 / 780$ & $18875 / 1 / 855$ & $17758 / 1 / 855$ \\
\hline Max. $/ \min . \Delta \rho / \mathrm{e} \AA^{-3}$ a & $0.362 /-0.394$ & $1.569 /-0.532$ & $0.464 /-0.306$ & $0.443 /-0.323$ \\
\hline $\mathrm{R}_{1} / \mathrm{wR}_{2}[\mathrm{I}>2 \sigma(I)]^{\mathrm{b}}$ & $0.0431 / 0.0813$ & $0.0558 / 0.1253$ & $0.0364 / 0.0643$ & $0.0364 / 0.0665$ \\
\hline $\mathrm{R}_{1} / \mathrm{wR}_{2}$ (all data) ${ }^{\mathrm{b}}$ & $0.0606 / 0.0890$ & $0.0712 / 0.1332$ & $0.0509 / 0.0682$ & $0.0511 / 0.0708$ \\
\hline Goodness-of-fit on $F^{2 c}$ & 1.011 & 1.030 & 0.946 & 0.967 \\
\hline Flack parameter $^{\mathrm{d}}$ & $0.032(12)$ & $0.05(3)$ & $-0.005(4)$ & $-0.005(5)$ \\
\hline
\end{tabular}

${ }^{\mathrm{a}}$ Largest difference peak and hole; ${ }^{\mathrm{b}} \mathrm{R}_{1}=\left[\sum\left(|| \mathrm{F}_{\mathrm{o}}|-| \mathrm{F}_{\mathrm{c}} \mid\right) / \sum\left|\mathrm{F}_{\mathrm{o}}\right|\right] ; \mathrm{wR}_{2}=\left[\sum\left[\mathrm{w}\left(\mathrm{F}_{\mathrm{o}}{ }^{2}-\right.\right.\right.$

$\left.\left.\left.\mathrm{F}_{\mathrm{c}}{ }^{2}\right)^{2}\right] / \sum\left[\mathrm{w}\left(\mathrm{F}_{\mathrm{o}}{ }^{2}\right)^{2}\right]\right]^{1 / 2} ;{ }^{\mathrm{c}}$ Goodness-of-fit $=\left[\sum\left[\mathrm{w}\left(\mathrm{F}_{\mathrm{o}}{ }^{2}-\mathrm{F}_{\mathrm{c}}{ }^{2}\right)^{2}\right] /(\mathrm{n}-\mathrm{p})\right]^{1 / 2} ;{ }^{\mathrm{d}}$ Absolute structure parameter. ${ }^{32}$

Computational section. Conformational searches and geometry optimizations were run with Spartan'10 (Wavefunction, Inc. Irvine, CA). Excited-state ECD calculations were run with Gaussian 09. ${ }^{56}$ Transition density plots were built using a locally modified version of the Gaussian 09 development program. The computational procedure was similar to the previously reported $\mathrm{Cu}$ analogs. ${ }^{20}$ Initial structures were generated starting from the available X-ray structure of $\Lambda-Z n-2 R$ complex (Figure 2). An initial structure with opposite configuration at the metal, $\Delta-\mathrm{Zn}-2 R$, was obtained by mirror inversion of the whole complex, followed by manual inversion of the carbon chirality centers only. Conformational searches were run with molecular mechanics, using the Molecular Merck force field (MMFF). The geometry around the metal was kept fixed by constraining the O-Zn and N-Zn bond lengths and the O-Zn-O and N-Zn-N bond angles at their respective X-ray values. All the remaining rotatable bonds were included in the conformational search (i.e., varied systematically) and optimized with MMFF. All structures thus obtained were re-optimized with DFT using B3LYP functional and 6-31G(d) basis set on all atoms. The model chromophoric structure (see Figure 7) was obtained from the lowest energy DFT structure of $\Lambda-Z n-2 R$ by replacing the $\mathrm{Zn}$ atom with hydrogen, and 1-(4'methoxyphenyl)ethyl by methyl.

Excited state calculations were run with the TDDFT method. A preliminary set of calculations was run on the lowest-energy structure of $\Lambda-Z n-2 R$ to test the performance of various DFT functionals and basis sets. The following functionals were tested: B3LYP, CAMB3LYP, M06 and $\omega$ B97X-D, and the two basis sets SDD and TZVP. Final calculations were run with the CAM-B3LYP/TZVP combination on DFT optimized structures of both $\Lambda-Z n-2 R$ and $\Delta-\mathrm{Zn}-2 R$ complexes, considering in both cases all DFT low-energy minima with Boltzmann population at $300 \mathrm{~K}$ above $1 \%$ (11 conformers for $\Lambda-Z n-2 R$ and 13 conformers for $\Delta-\mathrm{Zn}-2 R$. In each TDDFT calculation, 72 excited states (roots) were considered. The spectra were generated using the program SpecDis ${ }^{57}$ by applying a Gaussian band shape with $0.2 \mathrm{eV}$ exponential half- 
width. Rotational strengths calculated with the dipole-length gauge were employed, the differences with dipole-velocity values being negligible for most transitions.

Excitonic calculations were run with the routine EXAT (Excitonic Analysis Tool) ${ }^{58}$ EXAT employs a fragmentation procedure where the excitonic Hamiltonian, built using TDCAMB3LYP-computed transition densities and energies, is explicitly solved. ${ }^{59}$ Only the electricdipole/electric-dipole coupling was considered for comparison with the exciton chirality method where the intrinsic magnetic-dipole is usually neglected; however, we verified that the magnetic/electric coupling did not affect the sign of the ECD couplet. ${ }^{59}$ In EXAT calculations, the coupling potential was computed either using the TDDFT-calculated transition densities, or the point-dipole approximation. In this latter case the point dipole was placed in the middle between $\mathrm{C} 1-\mathrm{C} 2$ bond on each chromophore, and directed as shown in Figure 7. EXAT calculations were run on a simplified complex structure composed of two truncated ligands (obtained as described above) were adapted to the lowest-energy structure of compound $\Lambda$ - $\mathrm{Zn}$ $2 R$.

Supporting Information. Time dependent ${ }^{1} \mathrm{H}$ NMR spectra, additional packing diagrams, geometry-optimized structures, solid-state ECD spectra, and CIF files are reported. This material is available free of charge via the Internet at http://pubs.acs.org.

\section{ACKNOWLEDGMENT}

We acknowledge "Wazed Miah Science Research Centre", Jahangirnagar University, Dhaka, Bangladesh for elemental analyses data. Our sincere thanks to Professor Andrew Woolley, Department of Chemistry, University of Toronto, Canada, for running CD spectra. We thank Dr. Klaus Ditrich (ChiPros) at BASF AG, Ludwigshafen for providing the enantiopure $(R$ or $S)$-N-(Ar)ethylamines. Dr. Marcin Górecki is gratefully thanked for recording the solid-state ECD spectra.

\section{REFERENCES}

(1) (a) Urban, R.; Veghini, D.; Berke, H.; Beck, W. Z. Anorg. Allg. Chem. 2005, 631, 27152718. (b) Müller, G.; Brand, J. Z. Anorg. Allg. Chem. 2005, 631, 2820-2829. (c) Colacot, T. J.; Hosmane, N. S. Z. Anorg. Allg. Chem. 2005, 631, 2659-2668. (d) Brunner, H.; Keck, C. Z. Anorg. Allg. Chem. 2005, 631, 2555-2562. (e) Hauck, T.; Sünkel, K.; Beck, W. Z. Anorg. Allg. Chem. 2006, 632, 2305-2309. (f) Cozzi, P. G. Chem. Soc. Rev. 2004, 33, 410-421. (g) Sammis, G. M.; Jacobsen, E. N. J. Am. Chem. Soc. 2003, 125, 4442-4443. (h) Dreos, R.; Nardin, G.; 
Randaccio, L.; Siega, P.; Tauzher, G. Inorg. Chem. 2004, 43, 3433-3440. (i) Sammis, G. M.;

Danjo, H.; Jacobsen, E. N. J. Am. Chem. Soc. 2004, 126, 9928-9929. (j) Larrow, J. F.; Jacobsen, E. N. Top. Organomet. Chem. 2004, 6, 123-152.

(2) (a) Shibasaki, M.; Kanai, M.; Matsunaga, S.; Kumagai, N. Acc. Chem. Res. 2009, 42, 1117-1127. (b) Adão, P.; Costa Pessoa, J. O.; Henriques, R. T.; Kuznetsov, M. L.; Avecilla, F.; Maurya, M. R.; Kumar, U.; Correia, I. Inorg. Chem. 2009, 48, 3542-3561. (c) Xu, Z.-X.; Huang, Z.-T.; Chen, C.-F., Tetrahedron Lett. 2009, 50, 5430-5433. (d) Niemeyer, J.; Kehr, G.; Frohlich, R.; Erker, G. Dalton Trans. 2009, 3731-3741. (e) Escudero-Adán, E. C.; Belmonte, M. M. N.; Benet-Buchholz, J.; Kleij, A. W. Org. Lett. 2010, 12, 4592-4595. (f) Clegg, W.; Harrington, R. W.; North, M.; Pasquale, R. Chem. Eur. J. 2010, 16, 6828-6843. (g) Lee, J.-J.; Yang, F.-Z.; Lin, Y.-F.; Chang, Y.-C.; Yu, K.-H.; Chang, M.-C.; Lee, G.-H.; Liu, Y.-H.; Wang, Y.; Liu, S.-T.; Chen, J.-T. Dalton Trans. 2008, 5945-5956; (h) Jain, K. R.; Herrmann, W. A.; Kühn, F. E., Coord. Chem. Rev. 2008, 252, 556-568. (i) Chu, Z.; Huang, W.; Wang, L.; Gou, S. Polyhedron 2008, 27, 1079-1092.

(3) (a) Plater, M. J.; Gelbrich, T.; Hursthouse, M. B.; Silva, B. M. D. CrystEngComm 2006, 8, 895-903. (b) George, S.; Lipstman, S.; Muniappan, S.; Goldberg, I. CrystEngComm 2006, 8, 417-424. (c) Urban, R.; Beck, W. Z. Naturforsch. B: Chem. Sci. 2005, 60, 1071-1076. (d) Paul, B.; Nather, C.; Fromm, K. M.; Janiak, C., CrystEngComm 2005, 7, 309-319. (e) Hoffmueller, W.; Dialer, H.; Beck, W. Z. Naturforsch. B: Chem. Sci. 2005, 60, 1278-1286. (f) Zhou, X.; Zhao, J.; Santos, A. M.; Kuehn, F. E. Z. Naturforsch. B: Chem. Sci. 2004, 59, 1223-1228. (g) Santoni, G.; Rehder, D. J. Inorg. Biochem. 2004, 98, 758-764.

(4) (a) Wisser, B.; Lu, Y.; Janiak, C. Z. Anorg. Allg. Chem. 2007, 633, 1189-1192. (b) Wisser, B.; Janiak, C. Z. Anorg. Allg. Chem. 2007, 633, 1796-1800. (c) Klingelhöfer, S.; Wiebcke, M.; Behrens, P. Z. Anorg. Allg. Chem. 2007, 633, 113-119. (d) Ederer, T.; Herrick, R. S.; Beck, W. Z. Anorg. Allg. Chem. 2007, 633, 235-238. (e) Brunner, H.; Leyerer, H. J. Organomet. Chem. 1987, 334, 369-376. (f) Brunner, H.; Fisch, H. J. Organomet. Chem. 1987, $335,1-14$.

(5) (a) Pradeep, C. P.; Das, S. K. Polyhedron 2009, 28, 630-636. (b) Pradeep, C. P.; Zacharias, P. S.; Das, S. K. Inorg. Chem. Commun. 2008, 11, 89-93. (c) Pradeep, C. P.; Zacharias, P. S.; Das, S. K. Eur. J. Inorg. Chem. 2007, 5377-5389. (d) Pradeep, C. P.; Zacharias, P. S.; Das, S. K. Eur. J. Inorg. Chem. 2005, 3405-3408. (e) Fleischer, R.; Wunderlich, H.; Braun, M. Eur. J. Org. Chem. 1998, 1063-1070. 
(6) (a) Evans, C.; Luneau, D. J. Chem. Soc., Dalton Trans. 2002, 83-86. (b) Sakiyama, H.;

Okawa, H.; Matsumoto, N.; Kida, S. Bull. Chem. Soc. Jpn. 1991, 64, 2644-2647. (c) Sakiyama, H.; Okawa, H.; Matsumoto, N.; Kida, S. J. Chem. Soc., Dalton Trans. 1990, 2935-2939. (d) Ōkawa, H.; Nakamura, M.; Kida, S. Inorg. Chim. Acta 1986, 120, 185-189.

(7) (a) Akitsu, T. Polyhedron 2007, 26, 2527-2535. (b) Akitsu, T.; Einaga, Y. Polyhedron 2006, 25, 1089-1095. (c) Akitsu, T.; Einaga, Y. Polyhedron 2005, 24, 2933-2943. (d) Akitsu, T.; Einaga, Y. Polyhedron 2005, 24, 1869-1877. (e) Akitsu, T.; Einaga, Y. Acta Crystallogr. C 2004, 60, m640-m642. (f) Li, G.-P.; Yang, Q.-C.; Tang, Y.-Q.; Guan, Y.-D.; Shang, Z.-H. Acta Chim. Sin. 1987, 45, 421-425.

(8) (a) Brunner, H.; Zwack, T.; Zabel, M.; Beck, W.; Böhm, A. Organometallics 2003, 22, 1741-1750. (b) Brunner, H.; Oeschey, R.; Nuber, B. J. Chem. Soc., Dalton Trans. 1996, $1499-$ 1508. (c) Mandal, S. K.; Chakravarty, A. R. J. Chem. Soc., Dalton Trans. 1992, 1627-1633. (d) Mandal, S. K.; Chakravarty, A. R. J. Organomet. Chem. 1991, 417, C59-C62.

(9) (a) Gan, C.; Lai, G.; Zhang, Z.; Wang, Z.; Zhou, M.-M. Tetrahedron: Asymm. 2006, 17, 725-728. (b) Itagaki, M.; Hagiya, K.; Kamitamari, M.; Masumoto, K.; Suenobu, K.; Yamamoto, Y. Tetrahedron 2004, 60, 7835-7843. (c) Li, Z.; Liu, G.; Zheng, Z.; Chen, H. Tetrahedron 2000, 56, 7187-7191. (d) Prasad Rath, S.; Ghosh, T.; Mondal, S. Polyhedron 1997, 16, 4179-4186.

(10) (a) Chakravarthy, R. D.; Suresh, K.; Ramkumar, V.; Chand, D. K. Inorg. Chim. Acta 2011, 376, 57-63. (b) Zhang, C.; Rheinwald, G.; Lozan, V.; Wu, B.; Lassahn, P.-G.; Lang, H.; Janiak, C. Z. Anorg. Allg. Chem. 2002, 628, 1259-1268. (c) Flores-Lopéz, L. Z.; Parra-Hake, M.; Somanathan, R.; Walsh, P. J. Organometallics 2000, 19, 2153-2160. (d) Brunner, H.; Niemetz, M.; Zabel, M. Z. Naturforsch. B: Chem. Sci. 2000, 55, 145-154.

(11) (a) Zulauf, A.; Mellah, M.; Hong, X.; Schulz, E. Dalton Trans. 2010, 39, 6911-6935. (b) Lin, L.-L.; Liu, X.-H.; Feng, X.-M. Progr. Chem. 2010, 22, 1353-1361. (c) Gupta, K. C.; Kumar Sutar, A.; Lin, C.-C. Coord. Chem. Rev. 2009, 253, 1926-1946. (d) Abdi, S. H. R.; Kureshy, R. I.; Khan, N. H.; Mayani, V. J.; Bajaj, H. C. Catal. Surv. Asia 2009, 13, 104-131. (e) Gupta, K. C.; Sutar, A. K. Coord. Chem. Rev. 2008, 252, 1420-1450. (f) Matsumoto, K.; Saito, B.; Katsuki, T. Chem. Commun. 2007, 3619-3627.

(12) (a) Chamayou, A.-C.; Lüdeke, S.; Brecht, V.; Freedman, T. B.; Nafie, L. A.; Janiak C. Inorg. Chem. 2011, 50, 11363-11374. (b) Chamayou, A.-C.; Makhloufi, G.; Nafie, L. A.; Janiak, C.; Lüdeke, S. Inorg. Chem. 2015, 54, 2193-2203. 
(13) (a) Koch, D.; Hoffmuller, W.; Polborn, K.; Beck, W. Z. Naturforsch. B: Chem. Sci. 2001, 56, 403-410. (b) Karamé, I.; Jahjah, M.; Messaoudi, A.; Tommasino, M. L.; Lemaire, M. Tetrahedron: Asymm. 2004, 15, 1569-1581. (c) Karamé, I.; Tommasino, M. L.; Faure, R.; Lemaire, M. Eur. J. Org. Chem. 2003, 1271-1276.

(14) (a) Yang, Z.-H.; Wang, L.-X.; Zhou, Z.-H.; Zhou, Q.-L.; Tang, C.-C. Tetrahedron: Asymm. 2001, 12, 1579-1582. (b) Guo, P.; Wong, K.-Y. Electrochem. Commun. 1999, 1, 559563. (c) McKenzie, E. D.; Selvey, S. J. Inorg. Chim. Acta 1985, 101, 127-133. (d) Iglesias, A. L.; Aguirre, G.; Somanathan, R.; Parra-Hake, M. Polyhedron 2004, 23, 3051-3062.

(15) Enamullah, M.; Uddin, A. K. M. R.; Chamayou, A.-C.; Janiak, C. Z. Naturforsch. B: Chem. Sci. 2007, 62, 807-817.

(16) Enamullah, M.; Sharmin, A.; Hasegawa, M.; Hoshi, T.; Chamayou, A. C.; Janiak, C. Eur. J. Inorg. Chem. 2006, 2146-2154.

(17) Janiak, C.; Chamayou, A.-C.; Uddin, A. K. M. R.; Uddin, M.; Hagen, K. S.; Enamullah, M. Dalton Trans. 2009, 3698-3709.

(18) Enamullah, M.; Vasylyeva, V.; Janiak, C. Inorg. Chim. Acta 2013, 408, 109-119.

(19) Enamullah, M.; Islam, M. K. J. Coord. Chem., 2013, 66, 4107-4118.

(20) Enamullah, M.; Uddin, A. K. M. R.; Pescitelli, G.; Berardozzi, R.; Makhloufi, G.; Vasylyeva, V.; Chamayou, A.-C.; Janiak, C. Dalton Trans. 2014, 43, 3313-3329.

(21) Enamullah, M; Halim, M. A.; Islam,M. K.; Vasylyeva, V.; Janiak, C. Inorg. Chim. Acta 2015, 427, 103-111.

(22) Enamullah, M.; Quddus, M. A.; Hasan, M.R.; Pescitelli, G.; Berardozzi, R.; Reiß, G. J.; Janiak, C. Eur. J. Inorg. Chem. 2015, 2758-2768.

(23) Enamullah, M.; Islam, M. K.; Halim, M. A.; Janiak, C. J. Mol. Str. 2015, 1099, 154-162.

(24) Enamullah, M.; Quddus, M. A.; Hasan, M. R.; Pescitelli, G.; Berardozzi, R.; Makhloufi, G.; Vasylyeva, V.; Janiak, C. Dalton Trans., 2016, 45, 667-680.

(25) (a) Enamullah, M. J. Coord. Chem. 2011, 64, 1608-1616. (b) Enamullah, M. J. Coord. Chem. 2012, 65, 911-922.

(26) (a) Alam, M. S.; Rahman, M.; Enamullah, M. J. Bangladesh Chem. Soc. 2009, 22:2, $145-$ 152. (b) Royhan Uddin, A. K. M.; Enamullah, M. J. Bangladesh Chem. Soc. 2009, 22:1, 44-54.

(27) Enamullah, M.; Royhan Uddin, A. K. M.; Hogarth, G.; Janiak, C. Inorg. Chim. Acta 2012, 387, 173-180.

(28) Enamullah, M.; Royhan Uddin, A. K. M.; Hogarth, G. J. Coord. Chem. 2012, 65, 42634276. 
(29) (a) Damas, A.; Moussa, J.; Rager, M. N.; Amouri, H. Chirality 2010, 22, 889-895. (b) Mimassi, L.; Guyard-Duhayon, C.; Rager, M. N.; Amouri, H. Inorg. Chem. 2004, 43, 66446649. (c) Mimassi, L.; Cordier, C.; Guyard-Duhayon, C.; Mann, B. E.; Amouri, H.

Organometallics 2007, 26, 860-864.

(30) (a) Howson, S. E.; Allan, L. E. N.; Chmel, N. P.; Clarkson, G. J.; van Gorkum, R.; Scott, P. Chem. Commun. 2009, 1727-1729. (b) Amouri, H.; Gruselle, M.; Chirality in transition metal chemistry: Molecules, supramolecular assemblies and materials, John Wiley \& Sons, Ltd., 2008. (c) von Zelewsky A.; Mamula, O. J. Chem. Soc., Dalton Trans. 2000, 219-231. (d) von Zelewsky, A. Stereochemistry of Coordination Compounds, Wiley, Chichester, 1996. (e) Becker, J. M.; Barker, G J.; Clarkson, J.; van Gorkum, R.; Johal, G. K.; Walton, R. I.; Scott, P. Dalton Trans. 2010, 39, 2309-2326. (f) Knof, U.; von Zelewsky, A. Angew. Chem. 1999, 111, 312-333. (g) Seitz, M.; Stempfhuber, S.; Zabel, M.; Schütz, M.; Reiser, O. Angew. Chem. Int. Ed. 2005, 44, 242-245.

(31) (a) Janiak, C. J. Chem. Soc. Dalton Trans. 2000, 3885-3896. (b) Paulus, E. F.; Gieren, A. Handbook of Analytical Techniques, Wiley-VCH Verlag GmbH, New York, 2001, vol. 1, pp. 373-417. (c) Pescitelli, G.; Bari L. Di.; Berova, N. Chem. Soc. Rev. 2011, 40, 4603-4625.

(32) (a) Flack, H. D.; Sadki, M.; Thompson, A. L.; Watkin, D. J. Acta Crystallogr., Sect. A: Fundam. Crystallogr. 2011, 67, 21-34. (b) Flack, H. D.; Bernardinelli, G. Chirality, 2008, 20, 681-690. (c) Flack, H. D.; Bernardinelli, G. Acta Crystallogr., Sect. A: Fundam. Crystallogr. 1999, 55, 908-915. (d) Flack, H. Acta Crystallogr., Sect. A: Fundam. Crystallogr. 1983, 39, $876-881$.

(33) Enantiomers, racemates, and Resolutions. Jacques, J.; Collet A.; Wilen. S. H. Wiley, Malabar (FL, USA), 1981, pp. 342ff, 407.

(34) (a) Berova, N.; Di Bari L.; Pescitelli, G. Chem. Soc. Rev. 2007, 36, 914-931. (b) Harada, N.; Nakanishi, K. Circular Dichroic Spectroscopy - Exciton Coupling in Organic Stereochemistry, University Science Books, Mill Valley, CA, 1983; (c) Comprehensive Chiroptical Spectroscopy, eds. Berova, N.; Woody, R. W.; Polavarapu, P. L.; Nakanishi, K. Wiley \& Sons, Inc., Hoboken (NJ), 2012, ch. 4, pp. 115-166.

(35) Yamada, S. Coord. Chem. Rev. 1999, 190, 537. (b) Arai, N.; Sorai, M.; Seki, S. Bull. Chem. Soc. Jpn. 1972, 45, 2398. (c) Ashida, T.; Iwata, S.; Yamane, T.; Kakudo, M.; Takeuchi, A.; Yamada, S. Bull. Chem. Soc. Jpn. 1976, 49, 3502.

(36) (a) Shibuya, Y.; Nabari, K.; Kondo, M.; Yasue, S.; Maeda, K.; Uchida, F.; Kawaguchi, H. Chem. Lett. 2008, 37, 78-79. (b) Yang, L.;Powell, D.R.; Houser, R.P. Dalton Trans. 2007, 
955-964. (c) Addison, A.W.; Rao, T.N.; Reedijk, J.; van Rijn, J.; Verschoor, G. C. J. Chem. Soc., Dalton Trans. 1984, 1349-1356.

(37) (a) Nishio, M. CrystEngComm 2004, 6, 130-158. (b) Nishio, M.; Hirota, M.; Umezawa. Y. The $\mathrm{CH} / \pi$ interaction (Evidence, Nature and consequences), Wiley-VCH, 1998. (c) Umezawa, Y.; Tsuboyama, S.; Honda, K.; Uzawa. J.; Nishio, M. Bull. Chem. Soc. Jpn. 1998, 71, 1207-1213. (d) Janiak, C.; Temizdemir, S.; Dechert, S.; Deck, W.; Girgsdies, F.; Heinze, J.; Kolm, M. J.; Scharmann, T. G.; Zipffel, O. M. Eur. J. Inorg. Chem. 2000, 1229-1241. (e) Nishio, M, Phys. Chem. Chem. Phys. 2011, 13, 13873-13900; Nishio, M.; Umezawa, Y.; Honda, K.; Tsuboyama, S.; Suezawa, H. CrystEngComm 2009, 11, 1757-1788.

(38) Nichol G. S.; Clegg, W. CrystEngComm 2007, 9, 959-960.

(39) Steed, J. W. CrystEngComm 2003, 5, 169-179.

(40) Gavezotti, A. CrystEngComm 2008, 10, 389-398.

(41) (a) Desiraju, G. R. CrystEngComm 2007, 9, 91-92. (b) Ruiz, J.; Rodríguez, V.; Cutillas, N.; Hoffmann, A.; Chamayou, A.-C.; Kazmierczak, K.; Janiak, C. CrystEngComm 2008, 10, 1928-1938. (c) Vasylyeva, V.; Kedziorski, T.; Metzler-Nolte, N.; Schauerte, C.; Merz, K. Cryst. Growth Des. 2010, 10, 4224-4226.

(42) (a) Althoff, G.; Ruiz, J.; Rodríguez, V.; López, G.; Pérez, J.; Janiak, C. CrystEngComm 2006, 8, 662-665. (b) Hao, X.; Parkin, S.; Brock, C. P. Acta Crystallogr. Sect. B: Struct. Sci. 2005, 61, 689-699. (c ) Babu N. J.; Nangia, A. CrystEngComm 2007, 9, 980-983. (d) Chamayou, A.-C.; Biswas, C.; Ghosh A.; Janiak, C. Acta Cryst. 2009, C65, m311-m313. (e ) Makhloufi, G.; Schütte, K.; Janiak, C. Z. Kristallogr. NCS 2014, 229, 429-430. (f) Kirchner, M. T.; Bläser, D.; Boese, R.; Desiraju, G. R. CrystEngComm 2009, 11, 229-231.

(43) (a) Roy, S.; Banerjee, R.; Nangia, A.; Kruger, G. J. Chem. Eur. J. 2006, 12, 3777-3788. (b) Hernandez, J. O.; Portilla, J.; Cobo, J.; Glidewell, C. Acta Cryst. 2015, C71, 363-368. (c) Sarojini, B. K.; Yathirajan, H. S.; Hosten, E. C.; Betz, R.; Glidewell, C. Acta Cryst. 2015, C71, $59-64$.

(44) (a) Anderson, K. M.; Afarinkia, K.; Yu, H.-W.; Goeta, A. E.; Steed, J. W. Cryst. Growth Des. 2006, 6, 2109-2113. (b) Autschbach, J. Chirality, 2009, 21, E116-E152. (c) Autschbach, J.; Nitsch-Velasquez, L.; Rudolph, M. Top. Curr. Chem. 2011, 298, 1-98.

(45) (a) Andrés, R.; Gruselle, M.; Malézieux, B.; Verdaguer, M.; Vaissermann, J. Inorg. Chem. 1999, 38, 4637-4646. (b) Pescitelli, G.; Kurtán T.; Krohn, K. in Comprehensive Chiroptical Spectroscopy, ed. N. Berova, R. W. Woody, P. Polavarapu and K. Nakanishi, 
Wiley, New York, 2012, vol. 2, pp. 217-249; (c) Pescitelli, G.; Kurtán, T.; Flörke U.; Krohn, K. Chirality, 2009, 21, E181-E201.

(46) (a) Autschbach, J. Calculating Electronic Optical Activity of Coordination Compounds, In Comprehensive Inorganic Chemistry II, 2nd Edition, ed. Reedijk J.; Poeppelmeier, K. Elsevier, Amsterdam, 2013, Chapter 9.15, pp 407-426. (b) Telfer, S. G.; McLean T. M.; Waterland, M. R. Dalton Trans. 2011, 40, 3097-3108. (c) Ziegler, M.; von Zelewsky, A. Coord. Chem. Rev. 1998, 177, 257-300. (d) Mason, S. F. Molecular Activity and the Chiral Discriminations, Cambridge University Press, Cmabridge (UK), 1982.

(47) (a) Howard, I. A.; Zutterman, F.; Deroover, G.: Lamoen, D.; van Alsenoy, C. J.Phys. Chem. B 2004, 108, 19155-19162. (b) Kistler, K. A.; Spano F. C.; Matsika, S. J. Phys. Chem. B 2013, 117, 2032-2044.

(48) (a) Jurinovich, S.; Guido, C. A.; Bruhn, T.; Pescitelli, G.; Mennucci, B. Chem. Commun. 2015, 51, 10498-10501. (b) Jurinovich, S.; Pescitelli, G.; Di Bari, L.; Mennucci, B. Phys. Chem. Chem. Phys. 2014, 16, 16407-16418.

(49) Covington, C. L.; Nicu, V. P.; Polavarapu, P. L. J. Phys. Chem. A 2015, 119, 1058910601.

(50) APEX2, data collection program for the CCD area-detector system, Version 2.1-0, Bruker Analytical X-ray Systems: Madison (WI), 2006.

(51) SAINT, data reduction and frame integration program for the CCD area-detector system, Bruker Analytical X-ray Systems: Madison (WI), 2006.

(52) Sheldrick, G. Acta Crystallogr. Sect. A, 2008, 64, 112-122.

(53) Sheldrick G. M. Program SADABS, University of Göttingen: Göttingen, Germany, 1996.

(54) Brandenburg K. Diamond (Version 3.2), Crystal and Molecular Structure Visualization, Crystal Impact - K. Brandenburg \& H. Putz Gbr: Bonn, Germany, 2009.

(55) Spek, A. L. Acta Crystallogr. Sect. D, 2009, 65, 148-155. (b) Spek A. L. PLATON - A multipurpose crystallographic tool, Utrecht University: Utrecht, The Netherlands, 2005.

(56) Frisch, M. J.; Trucks, G. W.; Schlegel, H. B.; Scuseria, G. E.; Robb, M. A.; Cheeseman, J. R.; Scalmani, G.; Barone, V.; Mennucci, B.; Petersson, G. A.; Nakatsuji, H.; Caricato, M.; Li, X.; Hratchian, H. P.; Izmaylov, A. F.; Bloino, J.; Zheng, G.; Sonnenberg, J. L.; Hada, M.; Ehara, M.; Toyota, K.; Fukuda, R.; Hasegawa, J.; Ishida, M.; Nakajima, T.; Honda, Y.; Kitao, O.; Nakai, H.; Vreven, T.; Montgomery, J. A.; Peralta, J. E.; Ogliaro, F.; Bearpark, M.; Heyd, J. J.; Brothers, E.; Kudin, K. N.; Staroverov, V. N.; Kobayashi, R.; Normand, J.; Raghavachari, K.; Rendell, A.; Burant, J. C.; Iyengar, S. S.; Tomasi, J.; Cossi, M.; Rega, N.; Millam, J. M.; 
Klene, M.; Knox, J. E.; Cross, J. B.; Bakken, V.; Adamo, C.; Jaramillo, J.; Gomperts, R.;

Stratmann, R. E.; Yazyev, O.; Austin, A. J.; Cammi, R.; Pomelli, C.; Ochterski, J. W.; Martin, R. L.; Morokuma, K.; Zakrzewski, V. G.; Voth, G. A.; Salvador, P.; Dannenberg, J. J.;

Dapprich, S.; Daniels, A. D.; Farkas; Foresman, J. B.; Ortiz, J. V.; Cioslowski, J.; Fox, D. J.

Gaussian 09, Revision C.01, Wallingford CT, 2009.

(57) Bruhn, T.; Schaumlöffel, A.; Hemberger. Y.; Bringmann, G. Chirality, 2013, 25, 243249.

(58) Jurinovich, S.; Guido, C. A.; Mennucci, B. University of Pisa, Italy, 2014.

(59) Bruhn, T.; Pescitelli, G.; Jurinovich, S.; Schaumlöffel, A.; Witterauf, F.; Ahrens, J.; Bröring, M.; Bringmann, G. Angew. Chem. Int. Ed. 2014, 53, 14592-14595. 